\title{
Does design matter when visualizing Big Data? An empirical study to investigate the effect of visualization type and interaction use
}

\author{
Lisa Perkhofer ${ }^{1}$ D $\cdot$ Conny Walchshofer ${ }^{1} \cdot$ Peter Hofer $^{1}$ \\ Published online: 17 February 2020 \\ (C) The Author(s) 2020
}

\begin{abstract}
The need for good visualization is increasing, as data volume and complexity expand. In order to work with high volumes of structured and unstructured data, visualizations, supporting the ability of humans to make perceptual inferences, are of the utmost importance. In this regard, a lot of interactive visualization techniques have been developed in recent years. However, little emphasis has been placed on the evaluation of their usability and, in particular, on design characteristics. This paper contributes to closing this research gap by measuring the effects of appropriate visualization use based on data and task characteristics. Further, we specifically test the feature of interaction as it has been said to be an essential component of Big Data visualizations but scarcely isolated as an independent variable in experimental research. Data collection for the large-scale quantitative experiment was done using crowdsourcing (Amazon Mechanical Turk). The results indicate that both, choosing an appropriate visualization based on task characteristics and using the feature of interaction, increase usability considerably.
\end{abstract}

Keywords Interactive visualization - Usability · Multidimensional data visualization · Visual analytics · Big Data

Electronic supplementary material The online version of this article (https://doi.org/10.1007/s00187020-00294-0) contains supplementary material, which is available to authorized users.

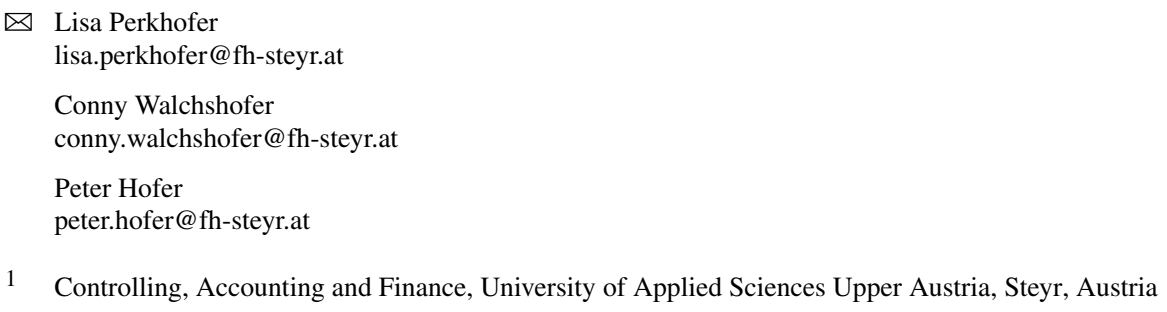




\section{Introduction}

One of the main purposes of management accounting is to provide decision-makers with relevant information for an easy, accurate, fast and rational decision-making process (Appelbaum et al. 2017; Dilla et al. 2010; Ohlert and Weißenberger 2015; Perkhofer et al. 2019b). Being able to fulfill this fundamental task is becoming more and more difficult as market dynamics increase (Eisl et al. 2012). The consequence is most likely a distortion of current working practice. Management accountants need to expand their scope from historical data reporting to real-time data processing, from using only in-house data to the inclusion of external data sources, from traditional paper based to interactive and online based reporting, and to shift the focus from reporting the past to predicting the future (Appelbaum et al. 2017; Goes 2014). To achieve this shift, new tools and technical instruments such as algorithms, appropriate management accounting systems and reporting software (Pasch 2019) and especially interactive data visualization are necessary (Perkhofer et al. 2019b; Janvrin et al. 2014; Bačić and Fadlalla 2016; Ohlert and Weißenberger 2015).

Visualizing Big Data proves to be of great importance when problems (or tasks) are high in complexity (Hirsch et al. 2015; Perkhofer 2019), or not sufficiently welldefined for computers to handle algorithmically, meaning human involvement and transparency is required (e.g. in fraud detection) (Munzner 2014; Kehrer and Hauser 2013; Dilla and Raschke 2015; Keim et al. 2008). Visualizing data means organizing information by spatial location and supporting perceptual inferences (Perkhofer et al. 2019a). Perceptual inferences are comparatively easy for humans to draw, as their visual sense is superior (with respect to fast programmable algorithms) and data transformation to the essential stores in human memory is astoundingly fast (Ware 2012; Keim 2001; Sweller 2010). Visualization thereby enhances the ability of both, searching and recognizing, and thus significantly enhances sense-making capabilities (Munzner 2014; Bačić and Fadlalla 2016).

However, in order to optimally support the human perceptual system, an appropriate and easy-to-use visualization needs to be presented to the decision-maker (Munzner 2014; Pike et al. 2009; Vessey and Galletta 1991; Perkhofer 2019; Falschlunger et al. 2016a). Especially when data and tasks increase in complexity, as is the case with high-dimensional datasets, traditional business charts are no longer able to convey all information in one chart. Therefore newer forms of visualizations, also called Big Data visualizations, have to be taken into account (Grammel et al. 2010). Big Data visualizations are unique in their purpose and designed to deal with, and present, larger amounts and various forms of data types (Perkhofer et al. 2019b). Novel forms with the goal of presenting multidimensional data, often used in visual analytics (Liu et al. 2017; Bačić and Fadlalla 2016), range from parallel coordinates and polar coordinates plots, over sunburst-, Sankey-, and heatmap-visualizations, to scatterplot matrices and parallel coordinated views (Liu et al. 2017; Albo et al. 2016; Bertini et al. 2011; Claessen and van Wijk 2011; Lehmann et al. 2010).

By the use of Big Data visualizations, the management accountant is able to show the whole dataset within one comprehensive visualization and is therefore able to generate new insights that would otherwise stay uncovered. For gaining insight, however, the visual display alone is not enough. The user needs to be able to interact with 
the interface (Elmqvist et al. 2011). Interacting in this context means using filter or selection techniques, drilling down to analyze the next layer of a data dimension, or also interchanging data dimensions or value attributes (Perkhofer et al. 2019b; Heer and Shneiderman 2012). Only if the user is able to interactively work with the dataset and answer predefined questions or questions that arise during the process of analysis, Big Data visualizations can unfold their full potential and new correlations, trends, or clusters can be detected for further use (Perkhofer et al. 2019a, c).

Unlike conventional charts used in everyday life (e.g. line, pie, or bar charts), new visualizations require a close focus on design and interaction in order to be considered useful (Liu et al. 2017; Kehrer and Hauser 2013; Elmqvist et al. 2011; Pike et al. 2009; Bačić and Fadlalla 2016). Unfortunately, for both the design and use of new visualization options, and the design and use of interaction, limited empirical research is available (Isenberg et al. 2013; Perkhofer et al. 2019b). Users still have to go through cost-intensive and unsatisfying trial and error routines in order to identify best practice instead of being able to rely on empirical evidence (van Wijk 2013). This led us to identify two concrete and pressing questions in current literature, addressed in this study:

(1) Appropriate use of new visualization types: Depending on data- and taskcharacteristics, some visualization types are claimed to outperform others when it comes to optimal decision-support. However, these claims are mostly based on their developers opinion or on small scale user studies rather than on experimental research (Isenberg et al. 2013; Perkhofer 2019). As multiple options to visualize Big Data are available, we limit the scope of this study to identify visualizations for multidimensional data. This is due to the fact, that it is impossible for traditional forms to show more than three attributes or three dimensions at the same time within one visualization. This, we think, highlights the importance and need of Big Data visualizations and demonstrates their benefits. Further, as a starting point to investigate Big Data visualizations we choose four frequently cited and actively used visualization types (details please see Table 1), namely the sunburst visualization, the Sankey visualization, the parallel coordinates plot and the polar coordinates plot (Bertini et al. 2011; Keim 2002; Shneiderman 1996). We wanted to investigate if one particular visualization type can outperform the other based on the three tasks identify, compare, and summarize (classification based on (Brehmer and Munzner 2013) using two different perspectives on the dataset (multiple hierarchy-levels vs. multiple attribute comparisons).

(2) Appropriate use of interaction techniques: Pike et al. claim that interaction "has not been isolated as an experimental variable" yet, therefore hindering direct causal interpretation on this highly discussed and frequently used visual analytics feature (Pike et al. 2009, p. 272). This is because most user studies concentrate on the visualization itself, while interaction is added as an integrated feature incorporated into the source code of the visual representation. Visualizations can be used and tested without interaction (as a static form), however, interaction does not work without the visualization itself (Kehrer and Hauser 2013). "Exactly what kind of degree of benefit is realized by allowing a user to interact with visual representation is still undetermined." (Pike et al. 2009, p. 272). Consequently, to 
answer this claim we isolate the effect of interaction and evaluate the difference between an almost static versus a highly interactive visualization.

Performance is measured by the three components of usability defined by ISO 9241 (efficiency, effectivity and satisfaction) as well as by one comprehensive sum-score for usability described and created by the authors. For data collection, we used the crowdsourcing platform Amazon Mechanical Turk resulting in a large sample size of $\mathrm{N}=2272$. Results obtained by MTurk have been shown to be congruent with lab experiments in the context of visual analytics (Harrison et al. 2014), allowing us to believe it is an appropriate and reliable platform to test our selected visualization options. Statistical analysis was based on MANCOVA (for simultaneously assessing efficiency, effectivity and satisfaction) or respectively ANCOVA (for assessing the sum-score for usability).

Results indicate that the used visualization type and the degree of interaction have an influence on efficiency and satisfaction, while the task type primarily influences effectivity. More precisely, from a users' perspective, information retrieval and therefore a fast and accurate decision is encouraged when being confronted with Cartesian based rather than Polar based visualization types (the Sankey visualization or the parallel coordinates plot rather than the polar coordinates plot or the sunburst visualization) and if visualizations are made accessible in a highly interactive form. For users to make effective decisions, the underlying task needs to be supported by the visualization type. For example, the task type summarize is executed more effectively if the data presented in the visualization is already condensed by dimensions (e.g. the Sankey or the sunburst visualization) while the task type identify is easier to execute if each single data entry is presented as a single property within the visualization (e.g. the parallel coordinates plot). These results can be seen as general guidelines for Big Data visualization use in the context of managerial accounting, however, also specific information on the used visualization types are presented in this experimental study.

The remainder of this paper is structured as follows: First, the general purpose of visualizations, specific visualization types and interaction techniques are discussed and the hypotheses four our experimental design are presented. In Sect. 3, the study design is laid out in detail before analysis is presented in Sect. 4. The last sections discuss and conclude our research findings, state limitations, and propose opportunities for further research in the context of interactive visualizations for multidimensional datasets.

\section{Theoretical background and hypotheses}

The fundamental goal of visualizations is to generate a particular insight or to execute a specific task by emphasizing distinct features of the underlying dataset (Lurie and Mason 2007; Anderson et al. 2011). Insights can either be the discovery of trends, correlations, associations, clusters, and events (that allow the generation or the verification of hypotheses), or the presentation of information to a particular audience by telling a persuasive and data-supported story for decision-making purposes (Brehmer and Munzner 2013). While telling a story mostly follows a standardized procedure 
such as reporting, the generation or verification of a hypothesis, in contrast, is typically ad hoc and unstructured (Perkhofer et al. 2019b). Especially in situations that ask for an ad hoc evaluation of a highly complex and large dataset, the use of Big Data visualization is of great importance (Chen and Zhang 2014; Falschlunger et al. 2016a). Consequently, users confronted with such problems have already established the use of Big Data visualizations. Pioneering examples can be found in fraud detection (Singh and Best 2019; Keim 2001), or when analyzing network traffic (Keim et al. 2006) as well as business models to reduce costs but maintain quality (Appelbaum et al. 2017). Further, Big Data visualizations are also customary in companies with a high focus on personalized marketing and social media to evaluate the implications of certain initiatives on product satisfaction and innovation (Keim 2001; Appelbaum et al. 2017).

Novel and interactive visualization types, such as those mentioned in the introduction (if used for their intended purpose and designed optimally), allow information to be uncovered which would otherwise stay hidden (Grammel et al. 2010). Currently, these new insights can be seen as a way to better attract customers or to optimize maintenance (Appelbaum et al. 2017), however, in the near future generating insight form Big Data will be a necessity to stay competitive (Perkhofer et al. 2019b). Nonetheless, in order to generate insight, the users and their abilities as well as needs have to be considered in the process of selection and design (Perkhofer 2019; Endert et al. 2014). While targeting specific users or user groups has already been identified as an essential part in standardized or scientific visualization use (Yigitbasioglu and Velcu 2012; Speier 2006), unfortunately, researchers and developers working on Big Data visualizations still put their sole focus on the generation of new visualization options to present a holistic view on the dataset (Perkhofer 2019). In doing so, they often fail to consider the users' precise needs and risk for their visualizations to misinform users or for not being used at all (Isenberg et al. 2013; van Wijk 2005; Perkhofer et al. 2019b).

In order to create or select appropriate visualizations, three stages are crucial according to Brehmer and Munzner: (1) encode (select and design appropriate visual forms), (2) manipulate (enable the user to interact with the data), and (3) introduce (enable the user to add additional data and save results) (Brehmer and Munzner 2013). In this paper, we concentrate on the selection and the design of appropriate, and most importantly interactive visualizations and therefore put emphasis only on the first two stages.

\subsection{Encode: choosing the visual representation and design}

Visual representation is synonymous with visual encoding and means transforming data into pictures. Analyzing data through a visual inference is easier and cognitively less demanding than looking at raw data because it allows for the identification of proximity, similarity, continuity, and closure (Zhou and Feiner 1998; Ohlert and Weißenberger 2015). Before we evaluate Big Data visualizations and their influencing factors based on usability (ISO 9241), a classification on the multiple choices proposed 
and presented to potential users (in literature and free libraries such as D3.js ${ }^{1}$ ) is necessary. We limit our investigation to frequently-cited and open-sourced visualization options (Perkhofer et al. 2019a, b) as the evaluation of all Big Data visualization options goes beyond the scope of this paper.

\subsubsection{Classification and description of frequently used Big Data visualizations}

For classification, we distinguish between two features: the type of data that can be represented in the proposed visualization (1a. multiple dimensions but only one attribute ${ }^{2} \rightarrow$ hierarchical visualization vs. 1b. multiple attributes but only one dimension $\rightarrow$ multi-attribute visualization) and the basic layout (2a. Polar or 2b. Cartesian-coordinates based visualizations). A summary on the identified visualizations used, is presented in Table 1 (Please note that the table does not claim to be exhaustive, but should rather be seen as an indicator of frequently-used or proposed visualization methods for multidimensional datasets, which is the selection criteria for our empirical analysis).

Based on this summary of highly cited and used visualization types we can conclude that both, a mix of Polar and Cartesian-coordinates based visualizations as well as a mix of hierarchical and multi-attribute based ones, are common. From this pool of options, we picked the most frequently cited pair of each category for comparison. For a better understanding of each individual visualization type, they are going to be explained in more detail in the following:

The sunburst visualization (Polar-coordinates based layout and hierarchical data structure): The sunburst visualization is one of the more frequently used visualization types compared to other and newer forms of visualizations (Perkhofer et al. 2019b). It projects the multiple dimensions of the dataset in a hierarchical dependent manner into rings and can therefore be mapped to be a Polar-coordinates based visualization option. The sunburst is a compact and space-filling presentation and shows the respective proportion of the total value by each dimensions and its sub-components by its angular size (Rodden 2014). Due to the strict structure of a sunburst, the innermost ring represents the highest hierarchical level and all dimensions dependent on it are represented in further rings to the outside (Keim et al. 2006). The position of the rings influences interpretation and therefore re-positioning of these dimensions (using another sequence of dimensions for the display of the rings) means gaining other and new valuable insights. Additionally, based on the Vega-light specification, categorical color scales are used to encode discrete data values, each representing a distinct category and sequential single-hue schemes to visually link related data characteristics (Satyanarayan et al. 2017).

The Sankey visualization (Cartesian-coordinates based layout and hierarchical data structure): The Sankey chart focuses on sequences of data, which can either be time-related or dependent on a hierarchical structure (Hofer et al. 2018). It is often used

\footnotetext{
1 D3.js (data driven documents) is a popular java-script based website for visualization researchers to share and exchange code for new visualization types; many visualization types available in software are first launched on D3.js.

2 An attribute is something measureable like revenues, costs, or contribution margins while a dimension is a way of clustering the data for analysis such as customer groups, product groups, or sales regions.
} 
Table 1 Highly cited and used visualization types identified for multidimensional data

\begin{tabular}{|c|c|c|c|}
\hline Visualization type & References & Data type & Layout \\
\hline \multirow{17}{*}{ Parallel coordinates plot } & Abi Akle et al. (2019) & \multirow[t]{17}{*}{ Multi-attribute } & \multirow{17}{*}{$\begin{array}{c}\text { Cartesian-coordinates } \\
\text { based visualization }\end{array}$} \\
\hline & Hofer et al. (2018) & & \\
\hline & Netzel et al. (2017) & & \\
\hline & Johansson and Forsell & & \\
\hline & (2016) & & \\
\hline & Kanjanabose et al. (2015) & & \\
\hline & Wang et al. (2015) & & \\
\hline & Harrison et al. (2014) & & \\
\hline & Heer and Shneiderman & & \\
\hline & Heinrich et al. (2012) & & \\
\hline & Claessen and van Wijk & & \\
\hline & $(2011)$ & & \\
\hline & Lehmann et al. (2010) & & \\
\hline & Henley et al. (2007) & & \\
\hline & Keim (2002) & & \\
\hline & Shneiderman (1996) & & \\
\hline & Inselberg and Dimsdale & & \\
\hline \multirow{10}{*}{ Sunburst visualization } & Hofer et al. (2018) & \multirow[t]{10}{*}{ Hierarchical } & \multirow{10}{*}{$\begin{array}{l}\text { Polar-coordinates } \\
\text { based visualization }\end{array}$} \\
\hline & Harrison et al. (2014) & & \\
\hline & Rodden (2014) & & \\
\hline & Kim and Draper (2014) & & \\
\hline & Mansmann et al. (2012) & & \\
\hline & Diehl et al. (2010) & & \\
\hline & Stab et al. (2010) & & \\
\hline & Draper et al. (2009) & & \\
\hline & Keim et al. (2006) & & \\
\hline & Stasko and Zhang (2000) & & \\
\hline \multirow[t]{7}{*}{ Polar coordinates plot ${ }^{\mathrm{a}}$} & Perkhofer et al. (2019a) & \multirow[t]{7}{*}{ Multi-attribute } & \multirow{7}{*}{$\begin{array}{l}\text { Polar-coordinates } \\
\text { based visualization }\end{array}$} \\
\hline & Liu et al. (2017) & & \\
\hline & Albo et al. (2016) & & \\
\hline & Harrison et al. (2014) & & \\
\hline & Claessen and van Wijk & & \\
\hline & Draper et al. (2009) & & \\
\hline & Elmqvist et al. (2007) & & \\
\hline \multirow[t]{7}{*}{ Treemap visualization } & Perkhofer et al. (2019a) & \multirow[t]{7}{*}{ Hierarchical } & \multirow{7}{*}{$\begin{array}{c}\text { Cartesian-coordinates } \\
\text { based visualization }\end{array}$} \\
\hline & $\begin{array}{l}\text { Wang et al. (2015) } \\
\text { Kim and Draper (2014) }\end{array}$ & & \\
\hline & Bostock et al. (2011) & & \\
\hline & Keim et al. (2006) & & \\
\hline & Songer et al. (2004) & & \\
\hline & Bruls et al. (2000) & & \\
\hline & Johnson et al. (1991) & & \\
\hline \multirow{4}{*}{ Sankey visualization } & Hofer et al. (2018) & \multirow[t]{5}{*}{ Hierarchical } & \multirow{4}{*}{$\begin{array}{c}\text { Cartesian-coordinates } \\
\text { based visualization }\end{array}$} \\
\hline & Chou et al. (2016) & & \\
\hline & Rodden (2014) & & \\
\hline & Riehmann et al. (2005) & & \\
\hline 8 & & & \\
\hline
\end{tabular}


Table 1 continued

\begin{tabular}{llll}
\hline Visualization type & References & Data type & Layout \\
\hline Heatmap visualization & Perkhofer et al. (2019a) & Multi-attribute & Cartesian-coordinates \\
& Barter and Yu (2018) & & based visualization \\
& Perrot et al. (2017) & & \\
& Severino (2015) & \\
& &
\end{tabular}

a Also known as star plot or radar chart

to present analysis based on elections, as it allows to highlight populations remaining loyal to the same party as well as populations changing their vote from one election to the other. Thus, the Sankey visualization is designed to present information of flow between multiple dimensions (e.g. processes, entities,...) (Chou et al. 2016). With regard to storytelling and sensemaking, interactions like re-ordering (changing the sequence of dimensions) and reducing the amount of visible nodes to minimize visual clutter are indispensable (Chou et al. 2016). In addition, for a consistent analysis of the data, it is necessary to find a way to highlight information across nodes by making use of selectors (Hofer et al. 2018).

The parallel coordinates plot (Cartesian-coordinates based layout and multiattribute data structure): The parallel coordinates plot is a very popular and strongly recommended visualization in the InfoVis (Information Visualization) community and highly cited in scientific research. This is due to the fact, that the parallel coordinates plot is one of the few visualizations that is able to present multiple attributes in one chart (Hofer et al. 2018; Perkhofer et al. 2019a). Two or more horizontal dimension axes are connected via polygonal lines at the height of the respective dimension value (Keim 2002; Perkhofer et al. 2019c). To do so, data is geometrically transformed (Keim 2001) and each line represents one data entry (e.g. an order, a sales entry). With respect to interpretation, Inselberg introduced common rules for the identification of correlations and trends (Inselberg and Dimsdale 1990)

- lines, which are parallel to each other suggest a positive correlation,

- lines crossing in an X-shape suggest a negative correlation, and

- lines crossing randomly, show no particular relationship.

Similar to a Sankey visualization, a user has to be able to re-arrange the axes on demand as only neighboring axis can be interpreted in a meaningful way (Perkhofer et al. 2019a). By making use of both, categorical/sequential single-hue color scales as well as filtering options, cluster analysis can be performed (Perkhofer et al. 2019c).

The polar coordinates plot (Polar-coordinates based layout and multi-attribute data structure): The polar coordinates plot is a radial projection of a parallel coordinates plot (Diehl et al.2010). Attributes are arranged radially, and each attribute value is presented proportionally to the magnitude of the value of each attribute with respect to their minimum and maximum value. Each line connecting the attribute values represents one data entry. Characteristic for a polar coordinates plot is the detection of dissimilarities and outliers. Nonetheless, it is difficult to compare the lengths across the uncommon axes (Diehl et al. 2010). Users encoding a polar coordinates plot try to interpret the 
area that appears as soon as all attributes are connected. Unfortunately, areas that appear at random depending on the loosely selected order of attributes, misinform the user. Further, areas are more difficult to compare than straight lines connecting data points (Kim and Draper 2014) and data points in outer layers cause areas to appear disproportionately bigger and therefore, angles lead to a harder assessment than straight lines due to their distortion (Perkhofer et al. 2019a). Effects have not been tested yet (Albo et al. 2016).

\subsubsection{Possible factors influencing usability of Big Data visualizations}

After presenting the most frequently used visualization options for Big Data, we are going to discuss possible influencing factors on their ability to encode specific information and making them accessible to their users. As already explained, each visualization type has the potential to uncover and present a different type of insight to its audience (supporting a different task), while at the same time hiding another (Perkhofer 2019). As theories and experimental research on the process of encoding for interactive visualizations for Big Data are limited, research from standard business graphics and dashboarding are used for hypotheses development (Falschlunger et al. 2016a; Speier 2006; Vessey and Galletta 1991; Perkhofer 2019; Yigitbasioglu and Velcu 2012). The purpose of this approach is to test existing principles on their applicability on interactive and new forms of visualizations and to shed light on the process of encoding in order to foster decision-making.

Previous findings have shown that the following factors (explained in more detail below) influence the ability of the user to successfully decode information given a chosen visualization option (Perkhofer 2019; Falschlunger et al. 2016a, b; Ware 2012; Vessey and Galletta 1991; Speier 2006):

(1) the design of the visualization,

(2) the dataset,

(3) the task, and

(4) the decision-maker characteristics (in particular previous experience and knowledge on reading and interpreting visualizations).

With respect to the design of the visualization, it has been shown that a low data-ink ratio (Tufte 1983) and the display of coherent information in juxtaposition (Perkhofer 2019) allows for a faster processing of information. Both of these principles are satisfied by Big Data visualizations, as they are designed to visualize the full dataset within one coherent visualization. However, a need for discussion can be identified when choosing a basic layout as visualizations are either based on a polarcoordinate or Cartesian-coordinate system and the basic layout fundamentally changes the way information needs to be decoded by the user (Rodden 2014). While in a polarcoordinates based visualizations, angles need to be assessed, the height of a column or the length of a line that needs to be compared within a Coordinates-based system. With respect to standardized business charts, Cartesian-coordinates based visualizations (scatterplots, line and bar charts) are known to outperform polar-coordinates ones (pie charts) (Diehl et al. 2010). However, this result on the most appropriate layout needs to be re-evaluated for Big Data visualizations as interactivity might change 
results (Albo et al. 2016). Further, the share of polar-based visualizations within the available and applied visualization tools is quite large and therefore deserves a closer look. This leads to our first hypotheses:

H1a: The basic layout influences usability of a visualization.

H1b: Cartesian-coordinate based visualization types outperform polar-coordinate based visualization types.

Next to the design, the underlying dataset influences usability. It is known, that data can only be assessed, as long as enough cognitive space is available for data processing (Sweller 2010; Atkinson and Shiffring 1968; Miller 1956). Otherwise, or more precisely in a state of information overload, a negative effect on effectivity, efficiency, and satisfaction can be identified (Bawden and Robinson 2009; Falschlunger et al. 2016a). It has also been demonstrated that data, which is presented in a familiar form (e.g. known since childhood) or which can be related to already known information stored in long-term memory, is processed faster and more accurately as the burden it poses on working memory is reduced (Perkhofer and Lehner 2019; Atkinson and Shiffring 1968).

As presented in Table 1, one needs to distinguish between hierarchical and multiattribute visualization types when dealing with multidimensional datasets. While for hierarchical visualizations only one attribute (e.g. one KPI such as sales) needs to be evaluated based on different levels and compositions of aggregation, for multiattribute visualizations multiple attributes need to be processed. For the latter, not only different measures need to be known and understood, but also they have to be analyzed in reference to each other for new insights to appear. Consequently, multiattribute visualizations are said to enhance the burden placed on the user (Falschlunger et al. 2016a) leading to the following hypotheses for our investigation:

H2a: The underlying dataset influences the usability of a visualization.

H2b: Hierarchy based visualizations types outperform multi-attribute based visualization types.

Without question and as already mentioned multiple times, tasks and insights differ with different visualization types. Matching the visualization to its respective task has been identified as a main influence in traditional visualization use. It has been shown that a mismatch increases cognitive load and consequently impairs decision-making outcome (Falschlunger et al. 2016a, b; Dilla et al. 2010; Shaft and Vessey 2006; Speier 2006; Perkhofer 2019). Up to now, the question of tables versus charts has been extensively tested resulting in a classification of spatial tasks (looking for trends, comparisons etc.) to be best supported by spatial visualizations (charts) and symbolic tasks (looking for specific data points) to be best supported by symbolic visualizations (tables) (Vessey and Galletta 1991). With respect to Big Data visualizations, a new classification of tasks has been established, namely identify (search for a specific data point), compare (compare two different data points or also two different aggregation levels), and summarize (generate overall insights by looking at the whole dataset) (Brehmer and Munzner 2013). However, these tasks have not yet been associated with visualization types or characteristics of visualization types.

Based on the fundamental activities that users have to perform and given the above presented task type classification, we hypothesize that the task identify is easier to 
perform if no previous aggregation based on different dimensions has influenced the visual appearance of the dataset. On the other hand, summarize should be easier to accomplish, if the dataset has already (at least to some extent) been aggregated and not every single data point is displayed in isolation. With respect to compare, results will be better for single data comparison tasks if the display shows every data-point in isolation, while results on the comparison of sub-dimensions (already aggregated data) will be better in hierarchical visualizations.

H3a: The task type influences the usability of a visualization.

H3b: Users will perform better with a multi-attribute visualization than with a hierarchy-based visualization when confronted with the task type identify.

H3c: Users will perform better with a hierarchy-based visualization than with a multi-attribute visualization when confronted with the task type summarize.

And finally, yet important, the factor user characteristics needs to be considered when choosing a specific visualization type. Results on standard business charts have demonstrated that choosing the right chart type (bar, line, pie, or column) has resulted in contradicting results given different user groups (Falschlunger et al. 2016a). Only if the factor previous experience, not only with the dataset and the KPIs but also with the respective visualization type used, is considered and included into the selection process, satisfying results are the consequence (Falschlunger et al. 2016b; Perkhofer and Lehner 2019). This can again be explained by the use of cognitive load theory: If the user has never seen the layout before a lot of cognitive resources are needed to read the visualization rather than to interpret the information that is represented by it. The more experience a user has with a specific visualization the more reading strategies exist and the more automated is the process of extracting data from the visualization leaving ample room for data interpretation (Perkhofer 2019).

H4: Previous experience/usage of the different visualization types positively effects usability.

Based on these findings, the different visualization options for representing multidimensional data presented and described above will most likely result in differences on usability depending on the task (identify, compare, summarize), the dataset used (hierarchical or multi-attribute data), their basic layout they represent (Cartesian-based or polar-based layout), and the level of previous experience. Nonetheless, we hope to find general rules and guidelines, similar to those of standard and scientific visualization use, to guide designers and users.

\subsection{Manipulate: using interaction to manipulate existing elements}

Visualizations designed to present large amounts of data greatly benefit from the process of interaction. In particular, the following processes are better supported by interactive visualizations when confronted with visual analytics tasks: detecting the expected, discovering the unexpected (generate hypotheses), and drawing datasupported conclusions (reject or verify hypothesis) (Kehrer and Hauser 2013). To be more specific, working with interactive visualizations is driven by a particular analytics task. However, when working interactively, analysis does not end by finding a 
proper answer to the initial task, but rather allows the generation and verification of additional and different hypotheses, which are then called insight (Pike et al. 2009). These are generated only because the user interactively works with the dataset, and the process of doing so increases engagement, opportunity, and creativity (Brehmer and Munzner 2013; Dilla et al. 2010).

As a consequence, visualizations presented in Table 1 are claimed to only become useful as soon as the user is able to interact with the data. Interaction is of such high importance, because the actions of a user demonstrate the "discourse the user has with his or her information, prior knowledge, colleagues and environment" (Pike et al. 2009 , p. 273). Further, the sequence of actions is not predefined but rather individual and dependent on the user. It thereby particularly supports the user's knowledge base and perceptual abilities (Dilla et al. 2010; Brehmer and Munzner 2013; Elmqvist et al. 2011; Dörk et al. 2008; Liu et al. 2017). Consequently, interaction requires active physical and mental engagement and throughout this process, understanding is increased and decision-making capabilities are enhanced (Pike et al. 2009; Pretorius and van Wijk 2005; van Wijk 2005; Wilkinson 2005; Dix and Ellis 1998; Buja et al. 1996; Shneiderman 1996). In a static form, only a general overview is presented to the user, however, without the opportunity of interaction, hypotheses verification, or further hypotheses generation is extremely limited (Hofer et al. 2018; Liu et al. 2017; Pike et al. 2009; Perkhofer et al. 2019b). This not only frustrates users, but also contradicts the well-known mantra of visual information seeking: "overview first, zoom and filter, then details on demand" (Shneiderman 1996). On a more practical level, interaction allows the user to filter, select, navigate, arrange, or change either the amount of data or the characteristics of the visual display (for details on the interaction techniques see Table 20 in the "Appendix").

Results on the proper use of interaction techniques are limited. Unfortunately, studies that have been conducted up to now, tend to blur the concept of visualization in combination with interaction (Pike et al. 2009). However, existing recommendations predominantly support the use of multiple interaction methods (Rodden 2014). "The more ways a user can 'hold' their data (by changing their form or exploring them from different angles and via different transformations), the more insight will accumulate" (Pike et al. 2009, p. 264). By intentionally clicking, scrolling and filtering the data, the user gains a deeper understanding of the relations within the given dataset. Interaction is therefore an essential part of the sense-making process and enhances the user's processing and sense-making capabilities (Shneiderman 1996). Building on previous literature, the following hypotheses are presented:

H5a: Interaction influences the usability of a visualization.

H5b: Users will perform better with a highly interactive visualization than with a mostly static one.

\section{Study design}

The purpose of this paper was directed toward the identification of an interactive visualization in order to present multidimensional data effectively and efficiently. Therefore 


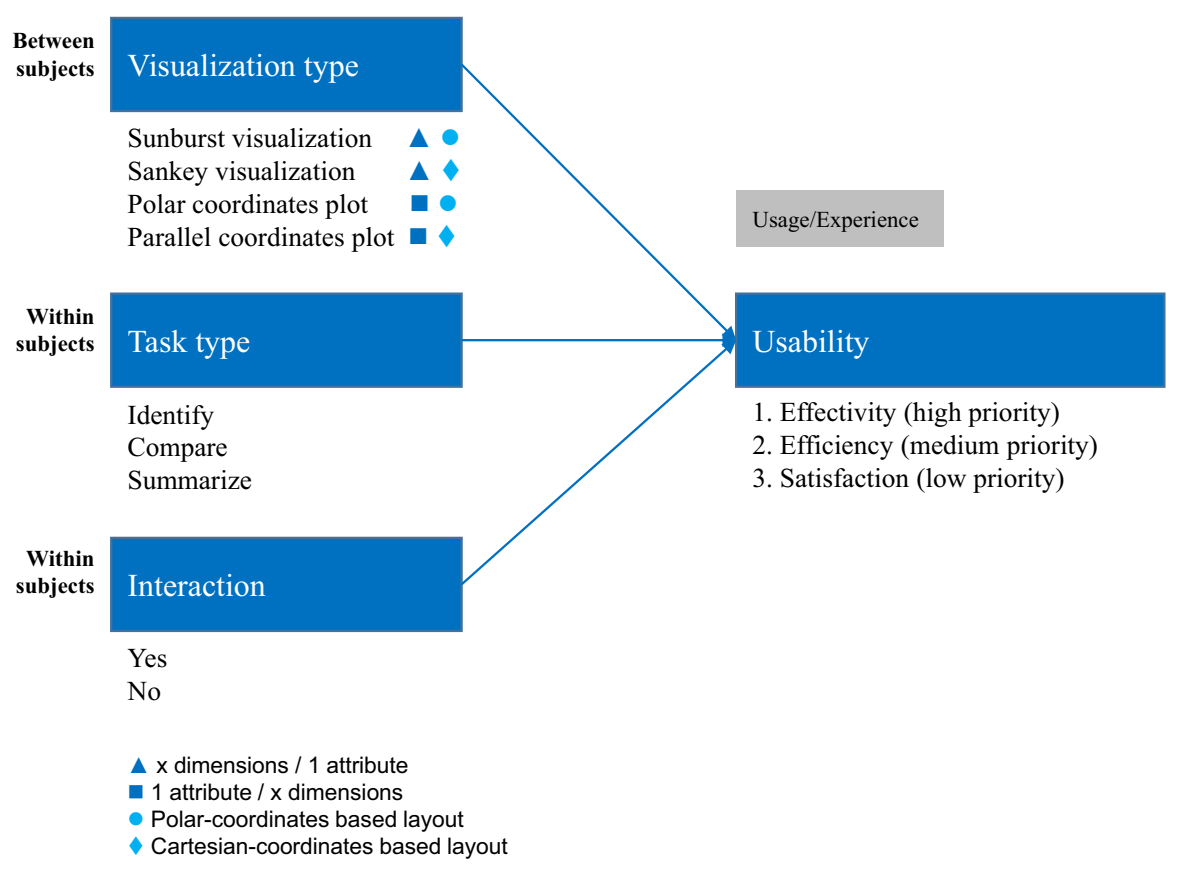

Fig. 1 Research model

a within and between experimental design $(4 \times 3 \times 2)$ was used. The visualization type was manipulated at four levels: For the experiment, we chose the most frequently researched and available visualization types, the sunburst visualization, the Sankey visualization, the parallel coordinates plot and the polar coordinates plot (please see Table 1). Two of the visualization types under investigation are in a Polar-based layout and two in a Cartesian-based one. Further, two out of four show a hierarchical dataset while the other two present a multi-attribute one. The task type was manipulated at three levels: The statements were based on Brehmer and Munzner's task taxonomy—identify, compare and summarize (Brehmer and Munzner 2013). And finally, interaction was manipulated at two levels (limited interaction, high interaction).

The experimental study was conducted using LimeSurvey and the crowdsourcing platform Amazon Mechanical Turk (MTurk). For each visualization type, a separate but identical experiment was created. Each participant evaluated only one visualization type, but had to assess various statements to simulate the process of hypothesis verification (= task types). Visualizations were coded based on the D3.js library, extended, and adjusted to fit our purpose (most significant changes needed to be implemented with respect to interaction techniques; available visualizations had limited options). Visualizations are available for download on the author's homepage or they can be accessed by clicking on the link presented in Table 22. Specifications on the dataset, the tasks, and the visualizations used are presented in the following subsections and the research model is presented in the following Fig. 1. 


\subsection{Data sample}

We used a self-generated data sample for our study as a basis to compare the different visualization types. The dataset simulated a wine trade company and consisted of 9961 records, whereby each record represented a customer's order. During construction of the sample, six finance experts designed key metrics typically used in trade companies to simulate a close-to-reality example for data exploration. The dataset consisted of 14 dimensions (order number, trader, grape variety, winemaker, state, etc.) and 12 attributes (gross margin, net margin, gross sales, net sales, discounts, gross profit, shipping costs, etc.) in total. As a result, our dataset can be described as being structured and shows no inconsistencies or missing values. Users were confronted with a large amount of data shown within one visualization, including multiple possible dimensions and attributes in order to find patterns, trends, or outliers. This allowed the assumption that confusion and misunderstanding based on the dataset were kept to a minimum (also confirmed in pre-tests). Each visualization used, without any filters active, showed the complete underlying dataset of 9961 records.

\subsection{Manipulation of the independent variables}

As already explained in Sect. 2, we tested four distinct visualization types. These four visualization types could be characterized by two features: by the structure of the data they were capable to display (hierarchical data vs. multi-attribute data) and by the overall layout of the visualization types (horizontal/Cartesian vs. radial/Polar). Additionally, interaction is the central component to understand and work with Big Data visualization tools. Therefore, by taking a closer look at already existing prototypes and literature, two interaction concepts per visualization type were designed to establish comparison and fairness, but also present each type in the best possible and most natural way. The used and virtually available visualization types and their respective interaction concepts are presented in Tables 21 and 22 in the "Appendix".

Based on the previously described dataset, statements in accordance with Brehmer and Munzner's task classification model for Big Data visualizations were created and presented to the participants for evaluation in randomized order. Participants were asked in the experimental conditions to assess the statements' truth (examples are presented in Table 2). Each task type was assessed twice per visualization-interaction combination.

\subsection{Dependent variable usability}

For assessing the quality of a visualization, the effects on user performance (efficiency and effectiveness) alone are not sufficient, instead one needs to measure the whole concept of usability (Pike et al. 2009; van Wijk 2013). Usability is defined by ISO 9241-11 and represents a combination of effectiveness, efficiency, and satisfaction (SAT) in order to present the user with the best possible solution. For effectiveness, we rated the number of statements answered correctly, while for efficiency, we measured the time for task execution (logged by LimeSurvey as soon as answers to a given task 
Table 2 Task types used including their predefined answer options

\begin{tabular}{|c|c|c|c|}
\hline Task type & \multicolumn{3}{|c|}{ Proxy of task used for this task classification } \\
\hline Identify & \multicolumn{3}{|c|}{$\begin{array}{l}\text { Wine \&Co9 sells fewer than } 3.000 \text { bottles of white wine } \\
\text { Options: This statement is correct. This statement is incorrect. This statement } \\
\text { cannot be answered }\end{array}$} \\
\hline Compare & \multicolumn{3}{|c|}{$\begin{array}{l}\text { Wine \&Co11 sells more red wine than Schenkenfelder } 2 \\
\text { Options: This statement is correct. This statement is incorrect. This statement } \\
\text { cannot be answered }\end{array}$} \\
\hline Summarize & \multicolumn{3}{|c|}{$\begin{array}{l}\text { Overall, more white wine is sourced from North/and South America than from Europe } \\
\text { Options: This statement is correct. This statement is incorrect. This statement } \\
\text { cannot be answered }\end{array}$} \\
\hline $\begin{array}{l}\text { Subtasks to calculate } \\
\text { usability score }\end{array}$ & $\begin{array}{l}\text { 1. Eliminate outliers and } \\
\text { correct direction for } \\
\text { efficiency }\end{array}$ & $\begin{array}{l}\text { 2. Use z-transformation } \\
\text { for effectivity, efficiency } \\
\text { and satisfaction and } \\
\text { adjust absolute levels }\end{array}$ & 3. Calculate sum score \\
\hline $\begin{array}{l}\text { Description and } \\
\text { assumptions } \\
\text { As well as steps } \\
\text { and formulas used }\end{array}$ & $\begin{array}{l}\text {-5\% percentile } \\
\text { excluded based on } \\
\text { experience in lab } \\
\text { experiments } \\
\text { (confusion vs. no } \\
\text { motivation) } \\
\text { - adjust direction of } \\
\text { task time based on } \\
\text { the direction of the } \\
\text { other two variables } \\
\text { effectivity and } \\
\text { satisfaction by } \\
\text { multiplying -1 } \rightarrow \\
\text { the higher the better }\end{array}$ & $\begin{array}{l}\text { - Calculate z-scores } \\
\text { (sample value- } \\
\text { mean)/ standard } \\
\text { deviation } \\
\text { - Adjust absolute } \\
\text { levels: } \\
\text { • calculate max and } \\
\text { min to measure the } \\
\text { absolute distance } \\
\text { - use the absolute } \\
\text { distance from the } \\
\text { largest parameter } \\
\text { (efficiency) for } \\
\text { level adjustment } \\
\text { (details see Table 6) }\end{array}$ & $\begin{array}{l}\text { - Add up values for } \\
\text { effectivity, efficiency, } \\
\text { and satisfaction }\end{array}$ \\
\hline
\end{tabular}

Fig. 2 Calculation of one comprehensive score for usability

were submitted). With respect to satisfaction, we collected data not per single task, but for each visualization and interaction level. Participants had to rate their satisfaction on a 5-point Likert scale (Question: Please rate your overall level of satisfaction with the visualization in the figure presented below. Please bear in mind the experimental tasks when filling out the scale. Answer options: very satisfied—satisfied—neutral—unsatisfied-very unsatisfied).

As usability is measured inconsistently throughout the literature, we provide insights into all three sub-components but also introduce one comprehensive measure for usability for better readability of results. In order to do so, we first calculate z-scores for the components before adjusting the absolute distance between min and max (the largest distance exists between efficiency; this distance is used to re-calculate min and max for effectivity and satisfaction). After data transformation, a sum score is calculated. Figure 2 documents the calculation and Fig. 3 shows details on the distribution of the used variables.

\subsection{Control variable}

Usage/Experience was assessed by analyzing each visualization type based on a 5point Likert scale (1-no use to 5-daily use) (Question: How often do you use the 


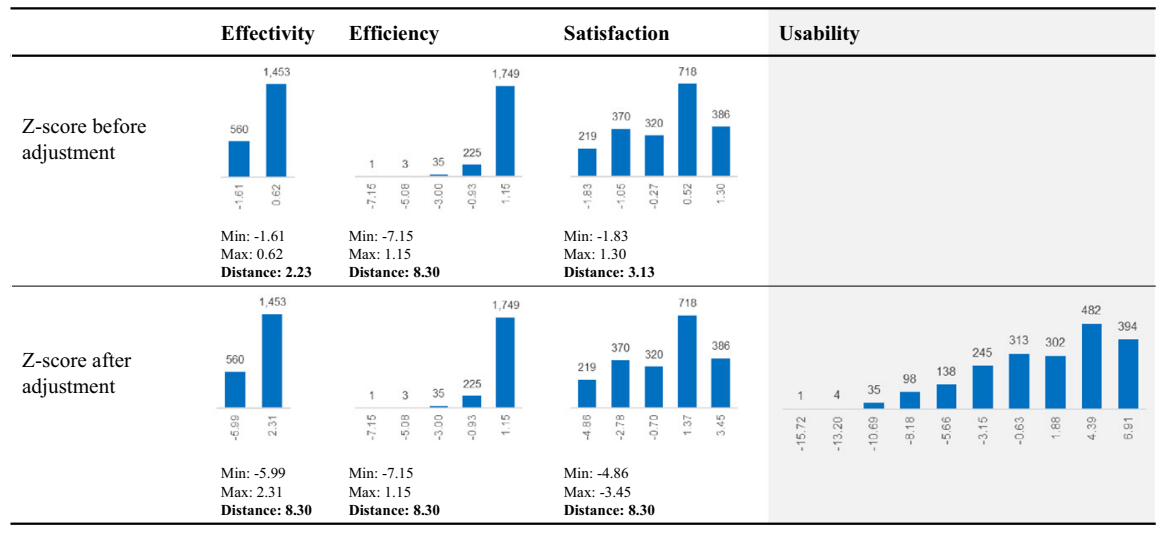

Fig. 3 Adjustment of z-scores to absolute levels of efficiency (for effectivity and satisfaction only the presented scores exists; for efficiency exact times observed during the study are used for analysis)

visualization in the figure presented below?). Insights on the obtained results are presented in Table 3.

\subsection{Procedure}

Before starting the experiment, an introduction served to explain the given dataset and the procedure of the study. Further, in order to work effectively and efficiently with the visualizations and the various interaction techniques used, we included a short video showing the visualization type in detail as well as all possible interaction techniques (the link was also available throughout the experiment by a link posted in the help section). For each visualization type and each interaction stage, not only the video but also a verbal explanation was included throughout the experiment.

After reading the introduction, the attention of the participants was tested to ensure quality by asking control questions. Only if 4 out of 6 questions were answered correctly, data was used for analysis. The static and the interactive layout were grouped and presented to the participants in randomized order (either they started with all questions based on the static or with all questions based on the interactive layout). Tasks within each layout were again presented in randomized order. After completing the experimental task, participants filled out a preference questionnaire concerning interaction and provided information on their experience with visual analytics and with the visualization type under investigation. Additionally, demographic information was collected.

The studies (one per visualization type) were launched on Amazon Mechanical Turk in June 2018 (Sunburst and Sankey visualization) and in January 2019 (Parallel Coordinates and Polar Coordinates Plot). Participants were compensated for their participation (10\$ per participant, the study lasted approximately $45 \mathrm{~min}$ ). Participants were only compensated for their invested time when the complete dataset was handed in and no response pattern (e.g. always choosing the same answer option, choosing "no answer" more than $30 \%$ of the time) could be identified. For data analysis, we 
Table 3 Details on control variable usage

\begin{tabular}{llll}
\hline Visualization type & & Static $(\%)$ & Interactive (\%) \\
\hline Sunburst visualization & Not at all & 46 & 60 \\
& Occasionally & 40 & 31 \\
& Monthly & 8 & 5 \\
Weekly & 0 & 4 \\
Sankey visualization & Daily & 6 & 0 \\
& Not at all & 51 & 51 \\
& Occasionally & 43 & 31 \\
Monthly & 4 & 10 \\
Parallel coordinates plot & Weekly & 2 & 8 \\
& Daily & 0 & 0 \\
& Not at all & 48 & 46 \\
& Occasionally & 40 & 38 \\
Polar coordinates plot & Monthly & 10 & 4 \\
& Weekly & 2 & 10 \\
& Daily & 0 & 2 \\
& Not at all & 63 & 53 \\
& Occasionally & 29 & 27 \\
& Monthly & 8 & 14 \\
& Weekly & 0 & 4 \\
& Daily & 0 & 2 \\
\hline
\end{tabular}

excluded the max $5 \%$ and min $5 \%$ of time needed per visualization to eliminate outliers. This is motivated by the researchers' previous experience in lab settings: We could observe extremely low task times in cases when not enough effort was put into solving the tasks (also leading to poor effectivity), and extremely high task times in cases of distractions. These steps were necessary to ensure high-quality data, even without observing participants during the execution of the experimental tasks.

\subsection{Participants}

Current evaluation practice for experimental research in the field of Information Visualization is to recruit undergraduate or graduate students to participate in a lab experiment. However, depending on their degree, students may have very little experience in visual analytics and thereby might cause misleading results (van Wijk 2013). Hence, we decided to recruit participants via Amazon Mechanical Turk, with the requirement of having at least the US Bachelor's degree as educational level, we introduce the topic and ask for knowledgeable participants in the survey description and, additionally we check for working experience and experience in visual analytics. Both, results on actual visualization use (see Table 3) and experience in visual analytics (see Table 4) show that participants were knowledgeable and therefore the 
right target group for our study. In total, we recruited 198 participants resulting in 2376 evaluable task assessments. Details on the participants per study can be found in Table 4.

\section{Results}

In the following, first results for each visualization type are going to be presented. This initial analysis shows whether interaction is a necessary component of a Big Data visualization (Sect. 4.1). For evaluation, MANCOVA is used to analyze our dependent variables individually (effectivity, efficiency, and satisfaction) and ANCOVA to analyze the generated sum score of usability. To check the quality of our results, we also conducted randomization tests to see whether a random allocation of results shows a difference in outcome to one of the variable's specification (number of resamples: 200). All randomization tests showed satisfying results, which are presented in the "Appendix". In the second part of this analysis, the effect of task type is going to be analyzed in more detail (Sect. 4.2).

\subsection{Results of interaction technique (per visualization type)}

\subsubsection{Descriptive statistics}

Table 5 shows descriptive statistics for the variables interaction technique and visualization type, which are the subjects of the first MANCOVA. While interaction seems to have a limited effect on effectivity, it seems to have a positive effect on both, efficiency and satisfaction. With respect to the visualization types, unfavorable results from the polar coordinates plot for the two variables efficiency and satisfaction stand out. Further, measures on effectivity and satisfaction show excess kurtosis as well as skewness of around -1 indicating that the measure is a little steeper and somewhat skewed to the left when compared to normal distribution. Response time shows a higher deviation from normality (skewness: -1.7 ; kurtosis: 4.0 ), as is typical for time related experiments with no time constraints imposed on the users.

Based on these results and by taking a closer look at the visualization types used, we can find an initial support for our hypothesis $1 a$ and $2 a$ that both, the layout as well as the dataset influence usability. While the layout seems to have a stronger influence on task time, the dataset has a stronger influence on response accuracy. With respect to hypothesis $1 b$, we can support the claim that Cartesian-based visualizations show a higher usability especially when looking at the interactive form. While for hypothesis $2 b$, we find only partial support as efficiency and satisfaction show a better performance for hierarchy-based visualizations while task accuracy is higher for multiattribute ones. Further, we find initial prooffor hypothesis $5 a$ as well as $5 b$ stating that interaction indeed has an influence and that usability is higher for interactive than for static visualizations. The next step is to test if these findings show significance in our multivariate linear model. 


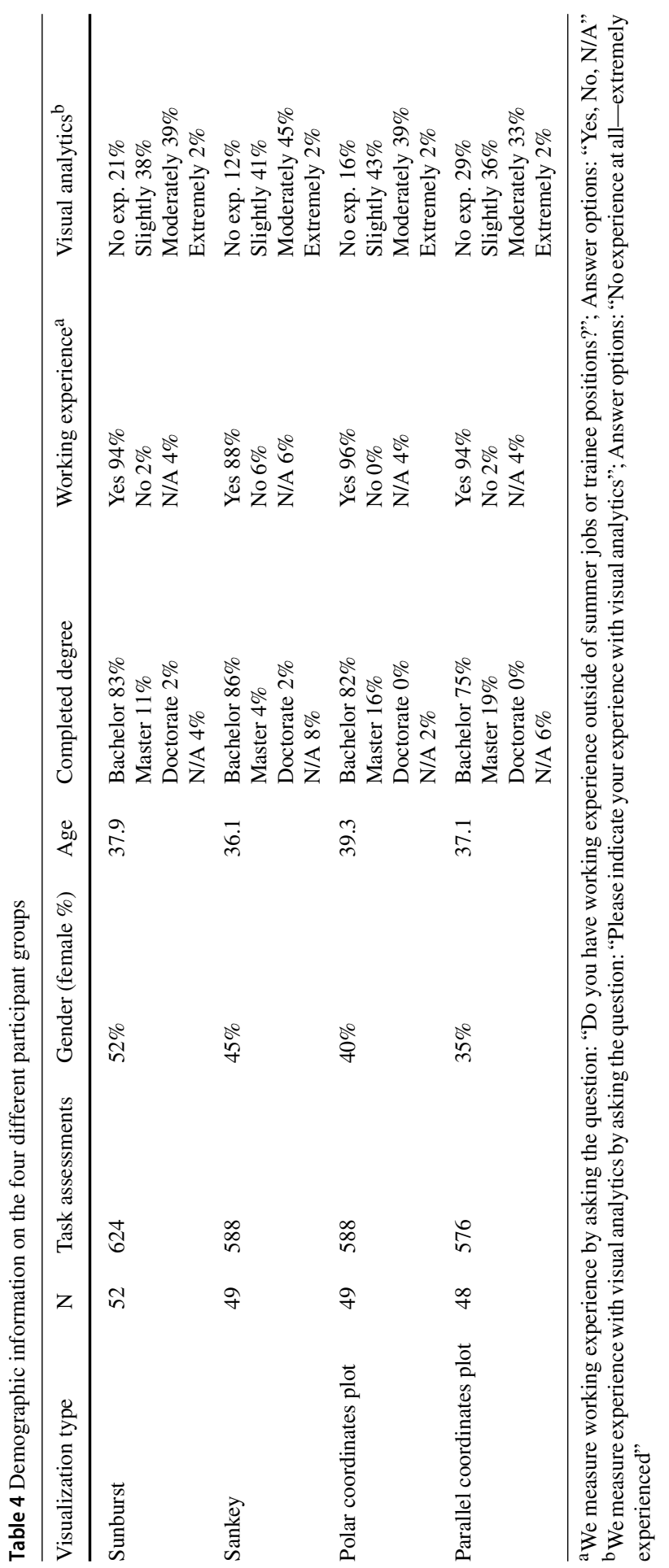


Table 5 Descriptive statistics —interaction technique per visualization type (means before z-transformation)

\begin{tabular}{|c|c|c|c|c|c|c|}
\hline \multirow[t]{2}{*}{ Means } & \multicolumn{2}{|c|}{ Effectivity (in \%) } & \multicolumn{2}{|c|}{ Efficiency (in s) } & \multicolumn{2}{|c|}{ Satisfaction (1-5) } \\
\hline & Static & Interactive & Static & Interactive & Static & Interactive \\
\hline Sunburst & 68.7 & 67.4 & 86.2 & 52.6 & 2.0 & 2.7 \\
\hline Sankey & 72.7 & 72.2 & 82.7 & 55.4 & 2.5 & 3.2 \\
\hline Parallel coordinates & 72.3 & 75.4 & 83.3 & 48.5 & 1.8 & 3.0 \\
\hline Polar coordinates & 78.9 & 68.9 & 143.0 & 90.1 & 1.1 & 2.6 \\
\hline$\varnothing$ & 73.4 & 71.0 & 99.8 & 62.3 & 1.8 & 2.9 \\
\hline$\varnothing$ Cartesian-based & 72.5 & 73.8 & 83.03 & 51.97 & 2.1 & 3.1 \\
\hline$\varnothing$ Polar-based & 74.2 & 70.0 & 116.86 & 63.23 & 1.5 & 2.7 \\
\hline$\Delta$ Layout & -1.7 & 3.8 & -33.83 & -11.26 & 0.6 & 0.4 \\
\hline$\emptyset$ Hierarchy based & 70.8 & 69.8 & 84.37 & 54.04 & 2.3 & 3.0 \\
\hline$\varnothing$ Multi-attribute based & 75.7 & 75.7 & 114.13 & 59.56 & 1.4 & 2.9 \\
\hline$\Delta$ Dataset & -4.9 & -5.9 & -29.76 & -5.52 & 0.9 & 0.1 \\
\hline
\end{tabular}

\subsubsection{MANCOVA for evaluating effectivity, efficiency, and satisfaction}

We decided to use MANCOVA for analysis despite Box's Test of equality of covariance matrices is significant $(p<0.001)$, as first $\mathrm{N}$ is high (approx. 500 per visualization type and 1000 per interaction concept—static vs. interactive) and therefore the test might be too sensitive to violations of equality. And second, because groups are roughly equal in size (between 250 and 270). As a consequence, we report Pillai's Trace and Wilks' Lambda as those two are the more conservative measures to minimize type I error.

Table 6 shows that the use of interaction has the strongest effect size in this model with a partial eta squared $\left(\eta^{2}\right)$ of 0.285 . Based on Cohen's classification (1969), this effect can be seen as strong $\left(\eta^{2} \geq 0.138\right)$, while the effect of visualization type is 0.091 and therefore considered to be medium in size $\left(\eta^{2} \geq 0.059\right)$. Usage (or previous experience with the particular visualization type) as well as the statistical interaction effect between visualization type and interaction technique (VisType $x$ Interaction) can be interpreted as small effects $\left(\eta^{2} \geq 0.010\right)$. After this initial analysis of the independent variables and the covariate, a more detailed analysis based on the three dependent variables follows in the Table 7 .

Table 7 shows that none of the independent variables under investigation has a significant effect on effectivity (response accuracy-RA). However, choosing the right visualization type has an effect on efficiency (response time-RT) and satisfaction. Further, using Big Data visualizations in an interactive form also show an effect on efficiency and satisfaction. Our introduced covariate usage (or previous experience with the particular visualization type) influences only the variable satisfaction, no effects can be found on efficiency and effectivity. These results allow us to confirm hypothesis 4 as well as $5 \mathrm{a}$.

Drilling further down in our analysis, results on post hoc Sidak indicate that for all visualization types the interactive form shows superior results for response time and 
Table 6 Multivariate test (interaction technique and visualization type)

\begin{tabular}{llllll}
\hline Effect & Test & Value & \multicolumn{1}{l}{ F } & Sig. & Partial eta squared \\
\hline Usage & Pillai's Trace & 0.023 & 16.011 & 0.000 & 0.023 \\
& Wilks' Lambda & 0.977 & 16.011 & 0.000 & 0.023 \\
VisType & Pillai's Trace & 0.272 & 66.589 & 0.000 & 0.091 \\
& Wilks' Lambda & 0.735 & 72.944 & 0.000 & 0.098 \\
Interaction & Pillai's Trace & 0.285 & 266.168 & 0.000 & 0.285 \\
& Wilks' Lambda & 0.715 & 266.168 & 0.000 & 0.285 \\
VisType x Interaction & Pillai's Trace & 0.039 & 9.000 & 0.000 & 0.013 \\
& Wilks' Lambda & 0.961 & 9.000 & 0.000 & 0.013 \\
\hline
\end{tabular}

Table 7 Test of between-subject effects (interaction technique and visualization type)

\begin{tabular}{llcrrl}
\hline Effect & Dependent variable & $\begin{array}{l}\text { Type III sum of } \\
\text { squares }\end{array}$ & F & Sig. & $\begin{array}{l}\text { Partial eta } \\
\text { squared }\end{array}$ \\
\hline Usage & RA_z & 0.746 & 0.747 & 0.387 & 0.000 \\
& RT_z & 0.180 & 0.214 & 0.644 & 0.000 \\
VisType & SAT_z & 0.816 & 134.610 & 0.000 & 0.063 \\
& RA_z & 5.421 & 1.811 & 0.143 & 0.003 \\
& RT_z & 303.862 & 143.305 & 0.000 & 0.177 \\
Interaction & SAT_z & 163.566 & 80.236 & 0.000 & 0.107 \\
& RA_z & 1.022 & 1.025 & 0.311 & 0.001 \\
& RT_z & 218.534 & 309.189 & 0.000 & 0.134 \\
VisType $x$ & SAT_z & 306.526 & 451.092 & 0.000 & 0.184 \\
Interaction & RA_z & 6.019 & 2.011 & 0.110 & 0.003 \\
& RT_z & 16.899 & 7.970 & 0.000 & 0.012 \\
R Squared & SAT_z & 32.665 & 16.024 & 0.000 & 0.023 \\
& RA_z & 0.007 & & & \\
& RT_z & 0.278 & & & \\
& SAT_z & 0.323 & & & \\
\hline
\end{tabular}

that the polar coordinates plot performs significantly worse than all other visualization types for Big Data. Regarding satisfaction, we can identify a superior visualization type (Sankey) as well as an inferior visualization type (polar coordinates). Further, we can identify again that interactive visualization types satisfy participants while static ones seem to frustrate them. (Note: Analysis based on effectivity is not presented, as no significant results could be obtained between-subjects).

The detailed analysis in Table 8 allows us to confirm hypothesis $5 b$ (based on efficiency and satisfaction; no result on effectivity).

Our analysis in Table 9 shows that Cartesian-coordinate based visualizations outperform Polar-coordinate based visualizations in terms of efficiency and satisfaction, while the difference in effectivity is not significant (confirming hypothesis 1b). Tak- 
Table 8 Significant pairwise comparisons_-interaction (post hoc Sidak)

\begin{tabular}{llll}
\hline Dependent variable & Significant pairs only & Mean difference & Sig. \\
\hline Efficiency RT_z & Static_interactive & -0.662 & 0.000 \\
Satisfaction SAT_z & Static_interactive & -0.784 & 0.000 \\
\hline
\end{tabular}

Table 9 Significant pairwise comparisons—visualization type (post hoc Sidak)

\begin{tabular}{llcc}
\hline Dependent variable & Significant pairs only & Mean difference & Sig. \\
\hline Effectivity RA_z & Hierarchy-multi-attribute & -0.079 & 0.077 \\
Efficiency RT_z & Sunburst_polar coordinates & 0.848 & 0.000 \\
& Sankey_polar coordinates & 0.869 & 0.000 \\
& Parallel coordinates—polar coordinates & 0.911 & 0.000 \\
& Polar_Cartesian & -0.499 & 0.000 \\
& Hierarchy-multi-attribute & 0.419 & 0.000 \\
Satisfaction SAT_z & Sunburst_Sankey & -0.398 & 0.000 \\
& Sunburst-polar coordinates & 0.393 & 0.000 \\
& Sankey-parallel coordinates & 0.407 & 0.000 \\
& Sankey-polar coordinates & 0.384 & 0.000 \\
& Parallel coordinates-polar coordinates & 0.384 & 0.000 \\
& Polar-Cartesian & -0.406 & 0.000 \\
& Hierarchy-multi-attribute & 0.417 & 0.000 \\
\hline
\end{tabular}

ing a closer look at the dataset used, we can find partial support for our hypothesis $2 b$. Hierarchy based visualizations perform better in terms of efficiency and satisfaction, while they perform worse (but only at a $p<0.1$ significance level) in terms of effectivity.

\subsubsection{ANCOVA for evaluating our sum score for usability}

After the initial analysis based on MANCOVA, where each dependent variable was looked at independently, we now investigate how a single score for usability influences results and interpretation. The following table presents all independent variables and the used covariate for usage (Table 10).

First, interpretation is easier, as only one dependent variable needs to be considered during analysis. However, statistical power and explainability is reduced considerably. The previously observed strong effects are reduced to be of medium strength and $\mathrm{r}^{2}$ is only 0.147 , indicating that only $15 \%$ of the variability in the dependent variable can be explained by our sum score for usability. Nonetheless, interpretation based on pairwise comparison stays the same. We can derive that interactive visualizations are superior when compared to static ones for all visualization types tested and we can conclude that the polar coordinates plot is inferior when compared to the other visualization types used in this study (Tables 11, 12). 
Table 10 Test of between-subject effects (visualization type and interaction technique)

\begin{tabular}{lcrll}
\hline $\begin{array}{l}\text { Dependent } \\
\text { variable }\end{array}$ & $\begin{array}{l}\text { Type III sum } \\
\text { of squares }\end{array}$ & F & Sig. & $\begin{array}{l}\text { Partial eta } \\
\text { squared }\end{array}$ \\
\hline Usage & 472.451 & 24.472 & 0.000 & 0.012 \\
VisType & 2228.604 & 38.480 & 0.000 & 0.055 \\
Interaction & 3295.185 & 170.686 & 0.000 & 0.079 \\
VisType $\times$ & 247.064 & 4.266 & 0.005 & 0.006 \\
$\quad \begin{array}{l}\text { Interaction } \\
\text { R squared }\end{array}$ & 0.147 & & & \\
\hline
\end{tabular}

Table 11 Significant pairwise comparisons_-interaction (post hoc Sidak)

\begin{tabular}{llll}
\hline Dependent variable & Significant pairs only & Mean difference & Sig. \\
\hline Usability & Static_-interactive & -2.570 & 0.000 \\
\hline
\end{tabular}

Table 12 Significant pairwise comparisons—visualization type (post hoc Sidak)

\begin{tabular}{llrr}
\hline Dependent variable & Significant pairs only & Mean difference & Sig. \\
\hline Usability & Sunburst-Sankey & -1.207 & 0.020 \\
& Sunburst_parallel coordinates & -1.133 & 0.037 \\
& Sankey_polar coordinates & 2.203 & 0.000 \\
& Parallel coordinates-polar coordinates & 2.129 & 0.000 \\
& Polar-Cartesian & -1.741 & 0.000 \\
& Hierarchy-multi-attribute & 1.229 & 0.000 \\
\hline
\end{tabular}

\subsection{Results on task type (per interactive visualization type)}

From our analysis in Sect. 4.1, we know that using Big Data visualization in an interactive form results in a better performance with respect to the two dependent variables efficiency and satisfaction which in turn increases usability. As a result, analysis based on task type is carried out only for interactive visualization types in order to concentrate on identifying the best visualization for specific task types. Again, we separately look at the dependent variables in a multivariate general linear model (Sect. 4.2.1) and use a univariate general linear model to evaluate the sum score for usability (Sect. 4.2.2).

\subsubsection{Descriptive statistics}

Table 13 shows mean values for the obtained data. What we can see from this analysis is, that the visualizations showing multiple attributes seem to outperform hierarchybased visualizations when working with the task type identify (when looking at effectivity), while for summarize no clear indication on superiority can be found. Regarding the distribution of the variables, we can again see a rather strong deviation 
Table 13 Descriptive statistics task type per visualization type (means before $\mathrm{z}$-transformation)

\begin{tabular}{|c|c|c|c|c|c|c|c|}
\hline \multirow[t]{2}{*}{ Means } & \multicolumn{3}{|c|}{ Effectivity (in \%) } & \multicolumn{3}{|c|}{ Efficiency (in s) } & \multirow[t]{2}{*}{$\mathrm{SAT}^{\mathrm{a}}$} \\
\hline & Identify & Compare & Summarize & Identify & Compare & Summarize & \\
\hline Sunburst & 51.1 & 77.2 & 80.4 & 49.0 & 55.5 & 54.0 & 2.7 \\
\hline Sankey & 57.1 & 74.4 & 84.7 & 53.2 & 52.7 & 60.2 & 3.2 \\
\hline Parallel Coord. & 81.0 & 67.9 & 77.4 & 50.1 & 46.8 & 48.7 & 3.0 \\
\hline Polar Coord. & 76.7 & 61.1 & 68.9 & 90.4 & 92.2 & 87.7 & 2.6 \\
\hline$\varnothing$ & 66.3 & 70.2 & 77.4 & 60.9 & 62.1 & 64.2 & 2.9 \\
\hline$\varnothing$ Hierarchy & 54.0 & 75.8 & 83.2 & 51.0 & 54.1 & 58.0 & 2.9 \\
\hline $\begin{array}{l}\varnothing \text { Multi- } \\
\text { attribute }\end{array}$ & 78.7 & 67.9 & 77.4 & 70.9 & 46.8 & 48.7 & 2.9 \\
\hline$\Delta$ Dataset & -24.7 & 7.9 & 5.8 & -19.9 & 7.3 & 9.3 & - \\
\hline
\end{tabular}

${ }^{\text {a }}$ Satisfaction had to be assessed based on the four visualization types and interaction; no distinction was used between task types

from normality for response time (skewness: -2.2 ; excess kurtosis: 6.8 ), while for the other two variables measures around -1 are indicated.

Based on these initial results, we can derive that the task type indeed has an influence on the variables used, however, the strongest influence can be identified for effectivity. Further, it seems that our hypothesis $3 b$ can be supported, while there might be little empirical support for $3 c$. Nonetheless, for a final résumé, statistical analysis from the next chapter is necessary.

\subsubsection{MANCOVA for evaluating effectivity, efficiency and satisfaction}

Again, Box's Test of equality of covariance matrices is significant $(p<0.001)$ but also for this analysis $\mathrm{N}$ is high (approx. 250 per visualization type and 350 per task type-identify, compare, and summarize) and groups are roughly equal in size (between and 84 and 92). Consequently, we report Pillai's Trace and Wilks' Lambda as those two are the more conservative measures.

Table 14 indicates that the visualization type has an influence on our multivariate general linear model and based on the effect size represented by $\eta^{2}$, the effect can be classified to be of medium size. Also, the covariate usage shows a significant effect and stands for an increased satisfaction along with an increase in previous experience with the respective visualization type. An effect is also visible for the statistical interaction of task type and visualization type (VisType $x$ TaskType), while no significance is shown for task type. Detailed analysis based on the dependent variables is presented in Table 10.

The more detailed analysis in Table 15 reveals that (as already known by the analysis in Sect. 4.1) the visualization type influences efficiency as well as satisfaction, while it has no effect on effectivity. More interestingly, this analysis also shows that task type influences effectivity (supporting H3a) and that there is a significant statistical interaction effect between visualization type and task type used (VisType x TaskType). 
Table 14 Multivariate test (task type and interactive visualization type)

\begin{tabular}{llllll}
\hline Effect & Test & Value & F & Sig. & Partial eta squared \\
\hline Usage & Pillai's Trace & 0.070 & 24.71 & 0.000 & 0.070 \\
& Wilks' Lambda & 0.970 & 24.71 & 0.000 & 0.070 \\
VisType & Pillai's Trace & 0.298 & 36.48 & 0.000 & 0.099 \\
& Wilks' Lambda & 0.710 & 40.58 & 0.000 & 0.108 \\
TaskType & Pillai's Trace & 0.011 & 1.82 & 0.091 & 0.005 \\
& Wilks' Lambda & 0.989 & 1.82 & 0.091 & 0.005 \\
VisType x TaskType & Pillai's Trace & 0.043 & 2.40 & 0.001 & 0.014 \\
& Wilks' Lambda & 0.957 & 2.41 & 0.001 & 0.014 \\
\hline
\end{tabular}

Table 15 Test of between-subject effects (task type and interactive visualization type)

\begin{tabular}{|c|c|c|c|c|c|}
\hline Effect & $\begin{array}{l}\text { Dependent } \\
\text { variable }\end{array}$ & $\begin{array}{l}\text { Type III } \\
\text { sum of } \\
\text { squares }\end{array}$ & $\mathrm{F}$ & Sig. & $\begin{array}{l}\text { Partial eta } \\
\text { squared }\end{array}$ \\
\hline \multirow[t]{3}{*}{ Usage } & RA_z & 2.081 & 2.114 & 0.146 & 0.002 \\
\hline & RT_z & 0.105 & 0.377 & 0.539 & 0.000 \\
\hline & SAT_z & 46.534 & 70.307 & 0.000 & 0.066 \\
\hline \multirow[t]{3}{*}{ VisType } & RA_z & 3.712 & 1.237 & 0.288 & 0.004 \\
\hline & RT_z & 92.759 & 30.920 & 0.000 & 0.251 \\
\hline & SAT_z & 36.058 & 23.019 & 0.000 & 0.052 \\
\hline \multirow[t]{3}{*}{ TaskType } & RA_z & 10.275 & 5.138 & 0.006 & 0.010 \\
\hline & RT_z & 0.207 & 0.140 & 0.690 & 0.001 \\
\hline & SAT_z & 0.020 & 0.010 & 0.985 & 0.000 \\
\hline \multirow{3}{*}{$\begin{array}{c}\text { VisType } \\
\text { x Task- } \\
\text { Type }\end{array}$} & RA_z & 36.847 & 6.236 & 0.000 & 0.036 \\
\hline & RT_z & 1.842 & 1.101 & 0.360 & 0.007 \\
\hline & SAT_z & 0.448 & 0.113 & 0.995 & 0.001 \\
\hline \multirow{3}{*}{$\begin{array}{l}\mathrm{R} \\
\text { Squared }\end{array}$} & RA_z & 0.051 & & & \\
\hline & RT_z & 0.257 & & & \\
\hline & SAT_z & 0.119 & & & \\
\hline
\end{tabular}

Table 16 Significant pairwise comparisons-task type

\begin{tabular}{llll}
\hline Dependent variable & Significant pairs only & Mean difference & Sig. \\
\hline Effectivity RA_z & Identify—summarize & -0.253 & 0.004 \\
\hline
\end{tabular}

This interaction effect states that depending on the visualization type used the difference in mean varies and for further insight pairwise comparison is needed to explain the connection (Table 16).

Response accuracy, without distinguishing between the visualization types, is significantly higher for the task type summarize than it is for the task type identify. Taking a closer look at the task type identify, it becomes obvious that the visualization types 
Table 17 Test of between-subject effects (task types and interactive visualization types)

\begin{tabular}{llrll}
\hline $\begin{array}{l}\text { Dependent } \\
\text { variable }\end{array}$ & $\begin{array}{l}\text { Type III sum } \\
\text { of squares }\end{array}$ & \multicolumn{1}{l}{ F } & Sig. & $\begin{array}{l}\text { Partial eta } \\
\text { squared }\end{array}$ \\
\hline Usage & 153.233 & 7.981 & 0.005 & 0.008 \\
VisType & 853.638 & 14.820 & 0.000 & 0.043 \\
TaskType & 133.150 & 3.467 & 0.032 & 0.007 \\
$\begin{array}{l}\text { VisType } x \\
\quad \text { TaskType }\end{array}$ & 443.878 & 3.853 & 0.001 & 0.023 \\
R Squared & 0.080 & & & \\
\hline
\end{tabular}

Table 18 Significant pairwise comparisons-task type

\begin{tabular}{llll}
\hline Dependent variable & Significant pairs only & Mean difference & Sig. \\
\hline Usability_Sum & Identify—summarize & -0.915 & 0.027 \\
\hline
\end{tabular}

that show disaggregated data (more attributes and only one dimension: parallel coordinates and polar coordinates) are superior, while visualization types that aggregate data based on multiple dimensions are inferior (sunburst and Sankey). The opposite is true for the task type compare (although differences are only significant at a $p<=0.1$ level) and for the task type summarize no significant difference between visualization types can be found. Based on these results hypothesis $3 b$ can be supported, while $3 c$ cannot.

With respect to response time and satisfaction, the same results as already presented in Sect. 4.1 are visible. Overall, polar coordinates are inferior to the other three visualization types. No significant difference can be found between the sunburst visualization, the Sankey visualization and the parallel coordinates plot. For satisfaction, the Sankey chart shows superior results while the polar coordinates shows the worst outcome.

\subsubsection{ANCOVA for evaluating our sum score for usability}

After analyzing the multivariate model, we again take a look at the univariate model based on our calculated sum score for usability. The following table shows the obtained results based on the between-subject effects (Table 17).

As already visible in the first analysis presented in Sect. 4.1.2, the sum score shows a reduced $\mathrm{r}^{2}$ (compared to RT and SAT) and also, the effect size of the independent variables is downsized from previous medium effects to small ones. Pairwise comparison reveals that the Sankey visualization and the parallel coordinates plot show the highest scores while the polar coordinates plot shows the worst (significant $p<0.05$ ). Further, we can again derive that irrespective of the visualization type used, the task type identify is more difficult to perform when Big Data visualizations are presented to the user than the task type summarize (especially when confronted with hierarchy based visualizations) (Table 18). 


\section{Conclusion and future work}

\subsection{Discussion and implications}

Reducing complexity by relying on a visual layout and enhancing problem-solving capabilities is the fundamental goal of visualizations (Ohlert and Weißenberger 2015). However, as datasets are increasing in complexity, conventional business charts (e.g. line, bar, and pie charts) are no longer sufficient and newer forms of visualizations especially designed to deal with this increasing complexity need to be applied (Perkhofer et al. 2019b). Within the discipline of Information Visualization many researchers are concerned with the creation of such new visualization types. Thus, a large pool of options already exists (Perkhofer 2019). However, what's missing, is to test their ability to inform and satisfy users within their explicit areas of application such as management accounting.

Thus, in this study we focus on a use-case that is based on data common within the discipline of management accounting and perform an experiment using knowledgeable participants in visual analytics. The dataset used was specifically created for this experiment to show a close-to-real data sample from a management-related perspective (Plaisant et al. 2008). Designing the data sample together with finance experts allowed us to draw from their experience and calculate metrics highly relevant for managerial accounting in a common trading company (in our case the wine trade). The contribution of this paper is the evaluation of multidimensional interactive visualizations for Big Data and its distinct components influencing usability in a large-scale quantitative experiment. By comparing four visualization types (the sunburst visualization, the Sankey visualization, the parallel coordinates plot, and the polar coordinates plot), three different task types (identify, compare, and summarize) as well as different interaction techniques (mostly static vs. interactive), their effect on decision-making (efficiency and effectiveness) and satisfaction could be evaluated. Recommendations based on these findings should help to increase the usability of these four visualization types in particular, but can also be applied to other types available (Fig. 4).

Summarizing the obtained results, the visualization type polar coordinates shows below-average performance in all comparisons and should not be used, while the parallel coordinates plot (Cartesian layout) as well as the Sankey visualization (again Cartesian layout) performed best. Using the right visualization type has a strong effect on efficiency and a medium effect on satisfaction, while no effect on effectivity could be detected. This analysis also indicates that horizontal or Cartesian based layouts outperform Polar visualizations. Further, our results imply that visualizations representing hierarchies are easier to interpret and work with, than visualization showing multiple attributes, however, when identification tasks need to be performed they are inferior.

With respect to task type, results demonstrate that the task type influences effectivity and therefore the most important variable of usability. In more detail, the task type summarize shows significantly better performance than the task type identify. Overall, we can state that the visualization results in better performance, when it fits to the task-identify asks rather for visualization types that show data in disaggregated 


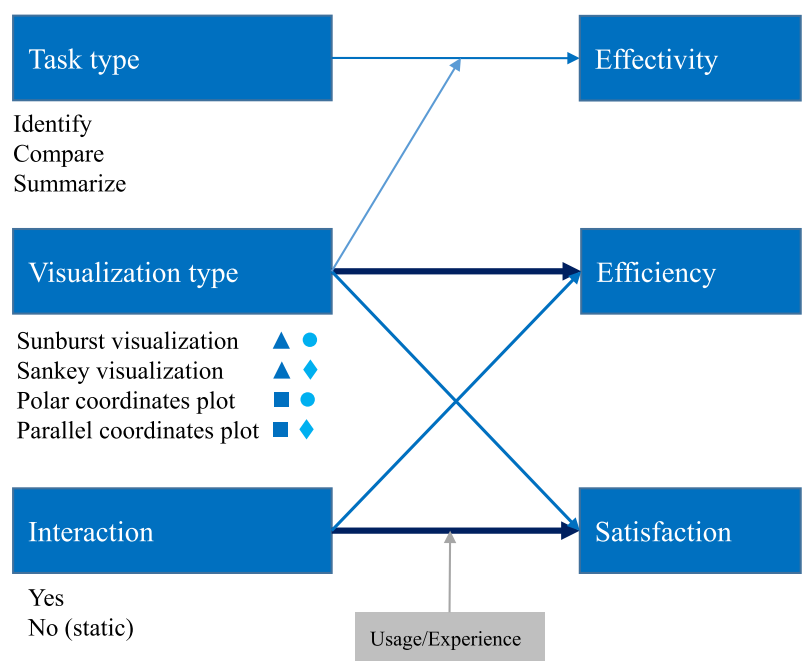

Fig. 4 Results on the research model. Directed effect size indicated by color and arrow thinkness $(\rightarrow$ small, $\rightarrow$ medium, and $\rightarrow$ large effect $)$

form (parallel and polar coordinates) while the task type summarize asks rather for visualizations that show data in an aggregated form. This is very much in line with previous research asking for a cognitive fit (Ohlert and Weißenberger 2015; Hirsch et al. 2015; Vessey and Galletta 1991).

Also clearly indicated by our results is the need for interaction when working with Big Data visualizations. The use of interaction has a strong effect on satisfaction and additionally, a medium effect on efficiency. Concerning our covariate usage, we can detect a significant influence on satisfaction while it has no effect on effectivity or efficiency. Results on all posted hypotheses are again presented and summarized in Table 19.

With respect to the evaluation methods used-multiple dependent variables versus one sum score-we could observe that a lot of explainability is lost by only looking at the sum score of usability instead of analyzing the three dependent variables effectivity, efficiency, and satisfaction independently. On the other hand, results based on the single score can be presented clearer and with respect to interpretation, no differences in recommendations to users are visible. From our perspective, this combined evaluation of the dependent variables and the sum score shows a clear picture on the effects tested in this study.

\subsection{Limitations and further research}

Of course, this study also includes some limiting factors that need to be discussed and considered when interpreting results. Limitations identified are an indication for further research opportunities that can be addressed in supplementary research endeavors:

Limited number of visualizations used: As already explained, we only analyzed a subset of visualization options available, however, a huge pool of further possibilities 
Table 19 Results on our hypotheses

\begin{tabular}{|c|c|c|}
\hline Hypothesis & Dependent variable & Results \\
\hline $\begin{array}{l}\text { H1a: The basic layout } \\
\text { influences usability of a } \\
\text { visualization }\end{array}$ & Usability & True \\
\hline $\begin{array}{l}\text { H1b: Cartesian-coordinate } \\
\text { based visualization types } \\
\text { outperform polar-coordinate } \\
\text { based visualization types }\end{array}$ & $\begin{array}{l}\text { Usability } \\
\text { Effectivity } \\
\text { Efficiency } \\
\text { Satisfaction }\end{array}$ & $\begin{array}{l}\text { True } \\
\text { No significance } \\
\text { True } \\
\text { True }\end{array}$ \\
\hline $\begin{array}{l}\text { H2a: The underlying dataset } \\
\text { influences the usability of a } \\
\text { visualization }\end{array}$ & Usability & Partly True \\
\hline $\begin{array}{l}\text { H2b: Hierarchy based } \\
\text { visualizations types } \\
\text { outperform multi-attribute } \\
\text { based visualization types }\end{array}$ & $\begin{array}{l}\text { Usability } \\
\text { Effectivity } \\
\text { Efficiency } \\
\text { Satisfaction }\end{array}$ & $\begin{array}{l}\text { Partly True } \\
\text { False } \\
\text { True } \\
\text { True }\end{array}$ \\
\hline $\begin{array}{l}\text { H3a: The task type influences } \\
\text { the usability of a visualization }\end{array}$ & $\begin{array}{l}\text { Usability } \\
\text { Effectivity } \\
\text { Efficiency } \\
\text { Satisfaction }\end{array}$ & $\begin{array}{l}\text { True } \\
\text { True } \\
\text { True }^{\mathrm{a}} \\
\text { No significance }\end{array}$ \\
\hline $\begin{array}{l}\text { H3b: Users will perform better } \\
\text { with a multi-attribute } \\
\text { visualization than with a } \\
\text { hierarchy-based visualization } \\
\text { when confronted with the task } \\
\text { type identify }\end{array}$ & Effectivity & True \\
\hline $\begin{array}{l}\text { H3c: Users will perform better } \\
\text { with a hierarchy-based } \\
\text { visualization than with a } \\
\text { multi-attribute visualization } \\
\text { when confronted with the task } \\
\text { type summarize }\end{array}$ & Effectivity & No significance \\
\hline $\begin{array}{l}\text { H4: Previous experience/usage } \\
\text { of the different visualization } \\
\text { types positively effects } \\
\text { usability }\end{array}$ & $\begin{array}{l}\text { Usability } \\
\text { Effectivity } \\
\text { Efficiency } \\
\text { Satisfaction }\end{array}$ & $\begin{array}{l}\text { True } \\
\text { No significance } \\
\text { No significance } \\
\text { True }\end{array}$ \\
\hline $\begin{array}{l}\text { H5a: Interaction influences the } \\
\text { usability of a visualization }\end{array}$ & Usability & True \\
\hline $\begin{array}{l}\text { H5b: Users will perform better } \\
\text { with a highly interactive } \\
\text { visualization than with a } \\
\text { mostly static one }\end{array}$ & $\begin{array}{l}\text { Usability } \\
\text { Effectivity } \\
\text { Efficiency } \\
\text { Satisfaction }\end{array}$ & $\begin{array}{l}\text { True } \\
\text { No significance } \\
\text { True } \\
\text { True }\end{array}$ \\
\hline
\end{tabular}

${ }^{\text {a }}$ Significant statistical interaction effect between visualization type and task type

exists. They range from additional forms of one comprehensive visualization, to the use of small multiples (multiple small visualizations put in juxtaposition such as parallel coordinates plot matrix or scatterplot matrix). Although the form of one comprehensive visualization is of relevance, it would be of special interest to investigate if a difference 
on mental demand and/or usability persists when using more than one visualization for displaying the dataset. These options need to be further explored.

Different interaction techniques depending on the visualization type: Results on all visualization types are directly comparable as they were tested with the same questions and the same data dimensions or attributes respectively. However, interaction techniques were used according to common practice, leaving us with different concepts using a different mix of individual techniques. We decided on this approach to ensure high external validity, knowing that we might introduce possible limiting factors for internal validity. We did not want to depart too much from the real world and thereby introduce simplification for the sake of fulfilling all requirements for a valid scientific experiment. However, we do not imply that this is the better approach in general, but it fits our purpose. The most important requirement for this study is that the visualization and the task are generic but also realistic.

Use of MTurk: While the use of MTurk comes with the advantage of a large pool of possible participants and fast survey completion rates, there are also some related limitations. First, during data collection, we as researchers have no control over the process. Participants could be disturbed or interrupted, drawing away the necessary attention that might be needed to successfully fulfill the required tasks. Therefore, special attention needs to be paid in the design of the questionnaire and quality checks need to be implemented to sort good from bad. Second, most workers live in the United States and India, which might introduce a cultural bias. However, workers tend to be more educated than the general population and therefore more complex issues can be posted on MTurk, which was important for our study. Further, specific characteristics of the workers (e.g. the need for a bachelor's degree) can be linked to the posted HIT (human intelligence tasks) in exchange for higher payment. Despite the possible drawbacks, a comparative study which was posted on MTurk and also executed in the lab in the context of visual analytics produced comparable results (Harrison et al. 2014). For this initial stage of our research, we need answers to many manipulations (design, dataset, correlation type...) and we therefore believe MTurk to be an appropriate platform.

No information on information retrieval process: The way information is retrieved from a visual display gives a lot of indications on design problems. Controlled experiments using eye-tracking have proven to be particularly useful in providing insight in the data retrieval process (Falschlunger et al. 2014, 2016a) and might be able to shed further light on the specific design issues. We could not make use of a controlled environment by using the crowdsourcing platform MTurk. Thus, we cannot assume that all participants have participated under the same conditions, meaning the same speed of internet, the same display accuracy of the end device, as well as the same environmental conditions (e.g. silent surrounding). Further, having enough cognitive resources is of high importance in order to uncover insight. Measuring cognitive load directly, for example by relying on physiological measurement methods such as eyetracking (Perkhofer and Lehner 2019) or heart rate variability (Hjortskov et al. 2004), might allow for more reliable results than by measuring on self-reported data.

Effectivity is measured dichotomous: The use of questions that are either correctly or incorrectly answered could be the reason why low effects on effectivity are visible within the model. Asking different questions that allow the assessment of effectivity 
using finer distinctions rather than 0 and 1 could be beneficial to gain further insight on this measure.

\subsection{Concluding remarks}

In conclusion, Big Data visualizations allow to show a large amount of data in one comprehensive visualization, however, a special focus needs to be placed on their design (including an appropriate layout and interaction techniques) as well as on the task they are supposed to support. The presented new visualizations (sunburst, Sankey, parallel coordinates plot, and polar coordinates plot) are better directed towards showing transaction-based data. Moreover, management accounting is an interesting area of application, however, the lack of experience of a user leaves them at a disadvantage in terms of interpretation and satisfaction (Perkhofer et al. 2019b). Without knowledge (or stored schemas in long-term memory) on how to interpret these visual forms and knowledge on how to operate them, insight cannot be triggered (Sweller 2010). This necessitates a detailed focus on user-centered visual and functional design, a fact that has been largely neglected so far (Isenberg et al. 2013). This study is a first attempt at closing this gap.

Acknowledgements Open access funding provided by University of Applied Sciences Upper Austria. The authors of this paper are thankful for the support of Hans-Christian Jetter and Thomas Luger and for the support of the University of Applied Sciences Upper Austria. The authors further gratefully acknowledge the Austrian Research Promotion Agency (FFG) Grant \#856316 USIVIS: User-Centered Interactive Visualization of "Big Data".

Open Access This article is licensed under a Creative Commons Attribution 4.0 International License, which permits use, sharing, adaptation, distribution and reproduction in any medium or format, as long as you give appropriate credit to the original author(s) and the source, provide a link to the Creative Commons licence, and indicate if changes were made. The images or other third party material in this article are included in the article's Creative Commons licence, unless indicated otherwise in a credit line to the material. If material is not included in the article's Creative Commons licence and your intended use is not permitted by statutory regulation or exceeds the permitted use, you will need to obtain permission directly from the copyright holder. To view a copy of this licence, visit http://creativecommons.org/licenses/by/4.0/.

\section{Appendix}

See Tables 20, 21 and 22. 
Table 20 Interaction techniques identified and clustered

\begin{tabular}{|c|c|c|}
\hline Interaction technique & Description & References \\
\hline Select: & $\begin{array}{l}\text { Selection allows highlighting data } \\
\text { based on certain options presented } \\
\text { to the user. The amount of visible } \\
\text { data stays the same, however, } \\
\text { highlighted data is moved into the } \\
\text { spotlight (e.g. through color } \\
\text { intensity). Multiple selectors are } \\
\text { possible. However, the more } \\
\text { selectors are active the higher the } \\
\text { mental demand posed on the user! } \\
\text { Examples: Linking and brushing, } \\
\text { drop-down, checkboxes, } \\
\text { radio-buttons, scrollable lists, slider, } \\
\text { directly clicking on elements in the } \\
\text { visualization, etc. }\end{array}$ & $\begin{array}{l}\text { Liu et al. (2017) } \\
\text { Johansson and Forsell (2016) } \\
\text { Brehmer and Munzner (2013) } \\
\text { Heer and Shneiderman (2012) } \\
\text { Pike et al. (2009) } \\
\text { Yi et al. (2007) } \\
\text { Chengzhi et al. (2003) } \\
\text { Keim (2001) }\end{array}$ \\
\hline Filter: & $\begin{array}{l}\text { In contrast to selecting, filtering } \\
\text { allows the exclusion data from } \\
\text { being visible and therefore actively } \\
\text { manipulates the amount of visible } \\
\text { data. Multiple active filters can be } \\
\text { very helpful to identify details along } \\
\text { multiple dimensions or facets, } \\
\text { however, it is difficult maintaining } \\
\text { overview (even more so if filters are } \\
\text { not visible) } \\
\text { Examples: Drop-down, checkboxes, } \\
\text { radio-buttons, scrollable lists, slider, } \\
\text { directly clicking on elements in the } \\
\text { visualization, etc. }\end{array}$ & $\begin{array}{l}\text { Liu et al. (2017) } \\
\text { Brehmer and Munzner (2013) } \\
\text { Kehrer and Hauser (2013) } \\
\text { Pike et al. (2009) } \\
\text { Yi et al. (2007) } \\
\text { Chengzhi et al. (2003) } \\
\text { Keim (2001) }\end{array}$ \\
\hline Navigate: & $\begin{array}{l}\text { Navigate alters the viewpoint of the } \\
\text { user. This can be used for instance } \\
\text { for geographical maps where you } \\
\text { can move the area of interest to } \\
\text { custom locations (directly by } \\
\text { mouse-click) } \\
\text { Examples: Zooming, panning, } \\
\text { rotating }\end{array}$ & $\begin{array}{l}\text { Johansson and Forsell (2016) } \\
\text { Brehmer and Munzner (2013) } \\
\text { Pike et al. (2009) } \\
\text { Yi et al. (2007) } \\
\text { Keim (2001) }\end{array}$ \\
\hline Arrange: & $\begin{array}{l}\text { Reorganizing elements of a } \\
\text { visualization spatially (data } \\
\text { dimensions or attributes) is of high } \\
\text { importance with regard to displays } \\
\text { where only neighboring datasets } \\
\text { can be analyzed (e.g. changing axis } \\
\text { within parallel coordinates plots or } \\
\text { Sankey visualizations) } \\
\text { Examples: Re-ordering axis, } \\
\text { re-ordering rows/columns, re-order } \\
\text { spatial layout if multiple } \\
\text { visualizations are involved }\end{array}$ & $\begin{array}{l}\text { Liu et al. (2017) } \\
\text { Chou et al. (2016) } \\
\text { Brehmer and Munzner (2013) } \\
\text { Pike et al. (2009) } \\
\text { Yi et al. (2007) }\end{array}$ \\
\hline
\end{tabular}


Table 20 continued

\begin{tabular}{|c|c|c|}
\hline Interaction technique & Description & References \\
\hline Change: & $\begin{array}{l}\text { Change is represented by the } \\
\text { possibility of altering the visual } \\
\text { representation itself. It is often } \\
\text { mentioned as being a high-level } \\
\text { interaction. However, following and } \\
\text { understanding a complete change of } \\
\text { the display can be cognitively } \\
\text { difficult to process and therefore } \\
\text { should be used sparingly } \\
\text { Examples: View reconfiguration } \\
\text { (changing the visualization type, } \\
\text { changing color schemes) }\end{array}$ & $\begin{array}{l}\text { Brehmer and Munzner (2013) } \\
\text { Kehrer and Hauser (2013) } \\
\text { Dörk et al. (2012) } \\
\text { Elmqvist et al. (2011) } \\
\text { Pike et al. (2009) } \\
\text { Yi et al. (2007) } \\
\text { Chengzhi et al. (2003) }\end{array}$ \\
\hline Aggregate: & $\begin{array}{l}\text { Using statistical measures to describe } \\
\text { multiple data points by one } \\
\text { measure. This can be very helpful to } \\
\text { generate quick insight. However, } \\
\text { even though statistical } \\
\text { characterization is a very powerful } \\
\text { approach, often valuable } \\
\text { information is lost } \\
\text { Examples: Mean, median, variance, } \\
\text { counts, summations }\end{array}$ & $\begin{array}{l}\text { Liu et al. (2017) } \\
\text { Chou et al. (2016) } \\
\text { Brehmer and Munzner (2013) } \\
\text { Heer and Shneiderman (2012) } \\
\text { Munzner (2014) }\end{array}$ \\
\hline
\end{tabular}

Table 21 Hierarchical prototypes used (self-coded) for experimental research

\begin{tabular}{|c|c|}
\hline Sunburst $\mathbf{\square}$ & Sankey $\mathbf{\square}$ \\
\hline $\begin{array}{l}\text { Interaction concept static: only mouse-over } \\
\text { https://usivis-survey.herokuapp.com/horizontal } \\
\text { Interaction concept interactive: mouse-over, } \\
\text { drill-through (filter) and drill-up (remove filter), } \\
\text { re-ordering of dimensions (from inner to outer } \\
\text { layer) } \\
\text { https://usivis-survey.herokuapp.com/sunburst/ } \\
\text { sortable }\end{array}$ & $\begin{array}{l}\text { Interaction concept static: Mouse-over } \\
\text { https://usivis-survey.herokuapp.com/sunburst/ } \\
\text { static4 } \\
\text { Interaction interactive: Mouse-over, brushing and } \\
\text { highlighting, multiple-selectors, re-ordering of } \\
\text { dimensions (from left to right), re-ordering of } \\
\text { dimension details (from top to bottom) } \\
\text { http://hgb-sankey-wine.herokuapp.com/ }\end{array}$ \\
\hline
\end{tabular}

Table 22 Multi-attribute prototypes used (self-coded) for experimental research

\begin{tabular}{|c|c|}
\hline Polar coordinates plot $\boldsymbol{\Delta} \boldsymbol{O}$ & Parallel coordinates plot $\boldsymbol{\Delta} \bullet$ \\
\hline $\begin{array}{l}\text { Interaction concept static: multiple-filters, } \\
\text { drop-down }\end{array}$ & $\begin{array}{l}\text { Interaction concept static: } \text { Multiple-filters, } \\
\text { range-slider }\end{array}$ \\
\hline $\begin{array}{l}\text { https://polarcoordinates.herokuapp.com/? } \\
\text { question=JoMac\&isMonochrome=true }\end{array}$ & $\begin{array}{l}\text { http://intervis.projekte.fh-hagenberg.at/USIVIS/ } \\
\text { PC1/examples/PC1.html }\end{array}$ \\
\hline $\begin{array}{l}\text { Interaction concept interactive: multiple-filters, } \\
\text { drop-down, re-ordering of attributes, } \\
\text { multi-color use to differentiate traders } \\
\text { (dimension details) }\end{array}$ & $\begin{array}{l}\text { Interaction concept interactive: Multiple-filters, } \\
\text { range-slider, re-ordering of attributes, } \\
\text { multi-color use to differentiate traders } \\
\text { (dimension details) }\end{array}$ \\
\hline $\begin{array}{l}\text { https://polarcoordinates.herokuapp.com/? } \\
\text { question=JoMac\&isMonochrome=false }\end{array}$ & $\begin{array}{l}\text { http://intervis.projekte.fh-hagenberg.at/USIVIS/ } \\
\text { PC3/examples/PC3.html }\end{array}$ \\
\hline
\end{tabular}


Table 23 Randomization check-visualization type (RT1)

\begin{tabular}{ll}
\hline $\begin{array}{l}\text { Sample results } \\
\text { (RT1) }\end{array}$ & $\begin{array}{l}\text { Resample results } \\
\text { (200 resamples) }\end{array}$ \\
\hline Mean: -47.12 & $\begin{array}{l}\text { Mean: } 0.12 / \text { SD: } 3.44 \\
\text { Probability of samples showing means above mean (sample): } 0.00 \% \\
\text { Probability of samples showing means below mean (sample): } 0.00 \% \\
\text { Two tails probability: } 0.00 \%\end{array}$ \\
\end{tabular}

Table 24 Randomization check-visualization type (RT2)

\begin{tabular}{ll}
\hline $\begin{array}{l}\text { Sample results } \\
\text { (RT2) }\end{array}$ & $\begin{array}{l}\text { Resample results } \\
\text { (200 resamples) }\end{array}$ \\
\hline Mean: -48.36 & $\begin{array}{l}\text { Mean: }-0.17 / \text { SD: } 3.16 \\
\text { Probability of samples showing means above mean (sample): } 0.00 \% \\
\text { Probability of samples showing means below mean (sample): } 0.00 \% \\
\text { Two tails probability: } 0.00 \%\end{array}$ \\
\hline
\end{tabular}

Table 25 Randomization check-visualization type (RT3)

\begin{tabular}{ll}
\hline $\begin{array}{l}\text { Sample results } \\
\text { (RT3) }\end{array}$ & $\begin{array}{l}\text { Resample results } \\
\text { (200 resamples) }\end{array}$ \\
\hline Mean: -50.60 & $\begin{array}{l}\text { Mean: } 0.07 / \text { SD: } 3.61 \\
\text { Probability of samples showing means above mean (sample): } 0.00 \% \\
\text { Probability of samples showing means below mean (sample): } 0.00 \% \\
\text { Two tails probability: } 0.00 \%\end{array}$ \\
\hline
\end{tabular}

Table 26 Randomization check-visualization type (SAT1)

\begin{tabular}{ll}
\hline $\begin{array}{l}\text { Sample results } \\
\text { (SAT1) }\end{array}$ & $\begin{array}{l}\text { Resample results } \\
\text { (200 resamples) }\end{array}$ \\
\hline Mean: -0.52 & Mean: $0.005 /$ SD: 0.072 \\
& $\begin{array}{l}\text { Probability of samples showing means above mean (sample): } 0.00 \% \\
\text { Probability of samples showing means below mean (sample): } 0.00 \% \\
\text { Two tails probability: } 0.00 \%\end{array}$ \\
\hline
\end{tabular}

\section{Randomization check 1: visualization type}

Randomization checks are only provided for significant pairwise comparison results in Sect. 4 (Tables 23, 24, 25, 26, 27, 28, 29, 30):

- RT1: Sunburst-polar coordinates plot

- RT2: Sankey—polar coordinates plot

- RT3: Parallel coordinates plot-polar coordinates plot

- SAT1: Sunburst-Sankey

- SAT2: Sunburst-polar coordinates

- SAT3: Sankey-parallel coordinates 
Table 27 Randomization check-visualization type (SAT2)

\begin{tabular}{ll}
\hline $\begin{array}{l}\text { Sample results } \\
\text { (SAT2) }\end{array}$ & $\begin{array}{l}\text { Resample results } \\
\text { (200 resamples) }\end{array}$ \\
\hline Mean: 0.52 & $\begin{array}{l}\text { Mean: } 0.006 / \text { SD: } 0.078 \\
\text { Probability of samples showing means above mean (sample): } 0.00 \% \\
\text { Probability of samples showing means below mean (sample): } 0.00 \% \\
\text { Two tails probability: } 0.00 \%\end{array}$ \\
\hline
\end{tabular}

Table 28 Randomization check-visualization type (SAT3)

\begin{tabular}{ll}
\hline $\begin{array}{l}\text { Sample results } \\
\text { (SAT3) }\end{array}$ & $\begin{array}{l}\text { Resample results } \\
\text { (200 resamples) }\end{array}$ \\
\hline Mean: 0.50 & Mean: 0.009/SD: 0.080 \\
& Probability of samples showing means above mean (sample): $0.00 \%$ \\
& Probability of samples showing means below mean (sample): $0.00 \%$ \\
& Two tails probability: $0.00 \%$ \\
\hline
\end{tabular}

Table 29 Randomization check-visualization type (SAT4)

\begin{tabular}{ll}
$\begin{array}{l}\text { Sample results } \\
\text { (SAT4) }\end{array}$ & $\begin{array}{l}\text { Resample results } \\
\text { (200 resamples) }\end{array}$ \\
\hline Mean: 1.05 & $\begin{array}{l}\text { Mean: } 0.007 / \text { SD: } 0.070 \\
\text { Probability of samples showing means above mean (sample): } 0.00 \% \\
\text { Probability of samples showing means below mean (sample): } 0.00 \% \\
\text { Two tails probability: } 0.00 \%\end{array}$
\end{tabular}

Table 30 Randomization check-visualization type (SAT5)

\begin{tabular}{ll}
\hline $\begin{array}{l}\text { Sample results } \\
\text { (SAT5) }\end{array}$ & $\begin{array}{l}\text { Resample results } \\
\text { (200 resamples) }\end{array}$ \\
\hline Mean: 0.54 & $\begin{array}{l}\text { Mean: }-0.001 / \text { SD: } 0.084 \\
\text { Probability of samples showing means above mean (sample): } 0.00 \% \\
\text { Probability of samples showing means below mean (sample): } 0.00 \% \\
\text { Two tails probability: } 0.00 \%\end{array}$ \\
\end{tabular}

- SAT4: Sankey—polar coordinates

- SAT5: Parallel coordinates-polar coordinates

\section{Randomization check 2: interaction type}

Randomization checks are only provided for significant pairwise comparison results in Sect. 4 (Tables 31, 32):

- RT1: Static-interactive

- SAT1: Static_interactive 
Table 31 Randomization check-interaction type (RT1)

\begin{tabular}{ll}
\hline $\begin{array}{l}\text { Sample results } \\
\text { (RT1) }\end{array}$ & $\begin{array}{l}\text { Resample results } \\
\text { (200 resamples) }\end{array}$ \\
\hline Mean: 37.13 & $\begin{array}{l}\text { Mean: } 0.27 / \text { SD: } 2.56 \\
\text { Probability of samples showing means above mean (sample): } 0.00 \% \\
\text { Probability of samples showing means below mean (sample): } 0.00 \% \\
\text { Two tails probability: } 0.00 \%\end{array}$ \\
\end{tabular}

Table 32 Randomization check-interaction type (SAT1)

\begin{tabular}{ll}
\hline $\begin{array}{l}\text { Sample results } \\
\text { (SAT1) }\end{array}$ & $\begin{array}{l}\text { Resample results } \\
(200 \text { resamples) }\end{array}$ \\
\hline Mean: -1.06 & $\begin{array}{l}\text { Mean: }-0.003 / \text { SD: } 0.059 \\
\text { Probability of samples showing means above mean (sample): } 0.00 \% \\
\text { Probability of samples showing means below mean (sample): } 0.00 \% \\
\text { Two tails probability: } 0.00 \%\end{array}$ \\
\hline
\end{tabular}

Table 33 Randomization check-interaction type (SAT1)

\begin{tabular}{ll}
\hline $\begin{array}{l}\text { Sample results } \\
\text { (RA1) }\end{array}$ & $\begin{array}{l}\text { Resample results } \\
\text { (200 resamples) }\end{array}$ \\
\hline Mean: -0.11 & $\begin{array}{l}\text { Mean: } 0.002 / \text { SD: } 0.034 \\
\text { Probability of samples showing means above mean (sample): } 0.00 \% \\
\text { Probability of samples showing means below mean (sample): } 0.00 \% \\
\text { Two tails probability: } 0.00 \%\end{array}$ \\
\hline
\end{tabular}

\section{Randomization check 3: task type}

Randomization checks are only provided for significant pairwise comparison results in Sect. 4 (Table 33):

- RA1: Identify-summarize

\section{References}

Abi Akle, A., Yannou, B., \& Minel, S. (2019). Information visualisation for efficient knowledge discovery and informed decision in design by shopping. Journal of Engineering Design, 30(6), 227-253. https:// doi.org/10.1080/09544828.2019.1623383.

Albo, Y., Lanir, J., Bak, P., \& Rafaeli, S. (2016). Off the radar. Comparative evaluation of radial visualization solutions for composite indicators. IEEE Transactions on Visualization and Computer Graphics, 22(1), 569-578. https://doi.org/10.1109/tvcg.2015.2467322.

Anderson, E. W., Potter, K. C., Matzen, L. E., Shepherd, J. F., Preston, G. A., \& Silva, C. T. (2011). A user study of visualization effectiveness using EEG and cognitive load. Computer Graphics Forum, 30(3), 791-800.

Appelbaum, D., Kogan, A., Vasarhelyi, M., \& Yan, Z. (2017). Impact of business analytics and enterprise systems on managerial accounting. International Journal of Accounting Information Systems, 25, 29-44. https://doi.org/10.1016/j.accinf.2017.03.003. 
Atkinson, R. C., \& Shiffring, R. M. (1968). Human memory. A proposed system and its control processes. In K. W. Spence \& J. T. Spence (Eds.), The psychology of learning and motivation (Vol. 2, pp. 89-195). New York: Academic Press.

Bačić, D., \& Fadlalla, A. (2016). Business information visualization intellectual contributions: An integrative framework of visualization capabilities and dimensions of visual intelligence. Decision Support Systems, 89, 77-86. https://doi.org/10.1016/j.dss.2016.06.011.

Barter, R. L., \& Yu, B. (2018). Superheat: An R package for creating beautiful and extendable heatmaps for visualizing complex data. Journal of Computational and Graphical Statistics: A Joint Publication of American Statistical Association, Institute of Mathematical Statistics, Interface Foundation of North America, 27(4), 910-922. https://doi.org/10.1080/10618600.2018.1473780.

Bawden, D., \& Robinson, L. (2009). The dark side of information. Overload, anxiety and other paradoxes and pathologies. Journal of Information Science, 35(2), 180-191.

Bertini, E., Tatu, A., \& Keim, D. A. (2011). Quality metrics in high-dimensional data visualization. An overview and systematization. IEEE Transactions on Visualization and Computer Graphics, 17(12), 2203-2212.

Bostock, M., Ogievetsky, V., \& Heer, J. (2011). D3: Data-driven documents. IEEE Transactions on Visualization and Computer Graphics, 17(12), 2301-2309.

Brehmer, M., \& Munzner, T. (2013). A multi-level typology of abstract visualization tasks. IEEE Transactions on Visualization and Computer Graphics, 19(12), 2376-2385. https://doi.org/10.1109/TVCG. 2013.124

Bruls, M., Huizing, K., \& van Wijk, J. J. (2000). Squarified treemaps. In W. de Leeuw \& R. van Liere (Eds.), Eurographics/IEEE VGTC. With assistance of IEEE computer society. IEEE VGTC symposium on visualization. Amsterdam, 29-30.05.2000 (pp. 1-10).

Buja, A., Cook, D., \& Swayne, D. F. (1996). Interactive high-dimensional data visualization. Journal of Computational and Graphical Statistics, 5(1), 78. https://doi.org/10.2307/1390754.

Chen, C. Philip L, \& Zhang, C.-Y. (2014). Data-intensive applications, challenges, techniques and technologies. A survey on Big Data. Information Sciences, 275, 314-347.

Chengzhi, Q., Chenghu, Z., \& Tao, P. (2003). The taxonomy of visaulization techniques and systems. Concerns between users and developers are different. In Proceedings of the Asia GIS 2003. Asia GIS conference. Wuhan, China, 16.-18.10.2003 (pp. 1-14).

Chou, J.-K., Wang, Y., \& Ma, K.-L. (2016). Privacy preserving event sequence data visualization using a Sankey diagram-like representation. In SIGGRAPH ASIA 2016 symposium on visualization (pp. 1-8). Macau: ACM.

Claessen, J. H. T., \& van Wijk, J. J. (2011). Flexible linked axes for multivariate data visualization. IEEE Transactions on Visualization and Computer Graphics, 17(12), 2310-2316. https://doi.org/10.1109/ TVCG.2011.201.

Diehl, S., Beck, F., \& Burch, M. (2010). Uncovering strengths and weaknesses of radial visualizations-an empirical approach. IEEE Transactions on Visualization and Computer Graphics, 16(6), 935-942. https://doi.org/10.1109/TVCG.2010.209.

Dilla, W., Janvrin, D. J., \& Raschke, R. (2010). Interactive data visualization. New directions for accounting information systems research. Journal of Information Systems, 24(2), 1-37. https://doi.org/10.2308/ jis.2010.24.2.1.

Dilla, W. N., \& Raschke, R. L. (2015). Data visualization for fraud detection. Practice implications and a call for future research. International Journal of Accounting Information Systems, 16, 1-22. https:// doi.org/10.1016/j.accinf.2015.01.001.

Dix, A., \& Ellis, G. (Eds.) (1998). Starting simple. Adding value to static visualisation through simple interaction. In $A V I$ '98 Proceedings of the working conference on Advanced visual interfaces. L'Aquila, Italy: ACM New York, NY, USA (AVI'98).

Dörk, M., Carpendale, S., Collings, C., \& Williamson, C. (2008). VisGets: Coordinated visualization for web-based information exploration and discovery. IEEE Transactions on Visualization and Computer Graphics, 14(6), 1205-1212.

Dörk, M., Riche, N. H., Ramos, G., \& Dumais, S. (2012). PivotPaths: Strolling through faceted information spaces. IEEE Transactions on Visualization and Computer Graphics, 18(12), 2709-2719.

Draper, G. M., Livnat, Y., \& Riesenfeld, R. F. (2009). A survey of radial methods for information visualization. IEEE Transactions on Visualization and Computer Graphics, 15(5), 759-776. https://doi.org/ 10.1109/TVCG.2009.23. 
Eisl, C., Losbichler, H., Falschlunger, L., Fischer, B., \& Hofer, P. (2012). Reporting design. Status quo und neue Wege in der Gestaltung des internen und externen Berichtswesens. In C. Eisl, H. Losbichler, C. Engelbrechtsmüller, M. Büttner, H. Wambach, \& A. Schmidt-Pöstion (Eds.), FH Oberösterreich, KPMG Advisory AG, pmOne AG.

Elmqvist, N., Moere, A. V., Jetter, H.-C., Cernea, D., Reiterer, H., \& Jankun-Kelly, T. J. (2011). Fluid interaction for information visualization. Information Visualization, 10(4), 327-340. https://doi.org/ $10.1177 / 1473871611413180$.

Elmqvist, N., Stasko, J., \& Tsigas, P. (Eds.) (2007). DataMeadow. A visual canvas for analysis of large-scale multivariate data. In 2007 IEEE symposium on visual analytics science and technology.

Endert, A., Hossain, M. S., Ramakrishnan, N., North, C., Fiaux, P., \& Andrews, C. (2014). The human is the loop: New directions for visual analytics. Journal of Intelligent Information Systems, 43(3), 411-435. https://doi.org/10.1007/s10844-014-0304-9.

Falschlunger, L., Eisl, C., Losbichler, H., \& Greil, A. (2014). Improving information perception of graphical displays. An experimental study on the display of column graphs. In V. Skala (Ed.), Proceedings of the 22nd WSCG. Conference on computer graphics, visualization and computer vision (WSCG). Pilsen, 02.-02.06.2014 (pp. 19-26).

Falschlunger, L., Lehner, O., \& Treiblmaier, H. (2016a). InfoVis: The impact of information overload on decision making outcome in high complexity settings. In Proceedings of the 15th annual PreICIS workshop on HCI research in MIS. SIGHCI 2016. Dublin, 11.12.2016. AIS Electronic Library: Association for Information Systems (Special Interest Group on Human-Computer Interaction), 1-6, Paper 3.

Falschlunger, L., Lehner, O., Treiblmaier, H., \& Eisl, C. (2016b). Visual representation of information as an antecedent of perceptive efficiency. The effect of experience. In Proceedings of the 49th Hawaii international conference on system sciences (HICSS). Koloa, HI, USA, 05.01.2016-08.01.2016 (pp. 668-676). IEEE.

Goes, P. B. (2014). Big data and IS research. MIS Quarterly, 38(3), 3-8.

Grammel, L., Tory, M., \& Storey, M. A. (2010). How information visualization novices construct visualizations. IEEE Transactions on Visualization and Computer Graphics, 16(6), 943-952.

Harrison, L., Yang, F., Franconeri, S., \& Chang, R. (2014). Ranking visualizations of correlation using Weber's law. IEEE Transactions on Visualization and Computer Graphics, 20(12), 1943-1952. https:// doi.org/10.1109/TVCG.2014.2346979.

Heer, J., \& Shneiderman, B. (2012). Interactive dynamics for visual analysis. Communications of the ACM, 55(4), 45-54. https://doi.org/10.1145/2133806.2133821.

Heinrich, J., Stasko, J., \& Weiskopf, D. (2012). The parallel coordinates matrix. In Eurographics conference on visualization (EuroVis). 33rd annual conference of the European association for computer graphics. Cagliari, Sardinia, Italy, 13.-18.05.2012 (pp. 1-5). European Association for Computer Graphics.

Henley, M., Hagen, M., \& Bergeron, D. (2007). Evaluating two visualization techniques for genome comparison. In E. Banissi (Ed.), 11th [IEEE] international conference information visualization. IV 2007 [proceedings] 4-6 July 2007, Zurich, Switzerland. IEEE Computer Society (pp. 1-6). Los Alamitos Calif., Washington D.C.: IEEE Computer Society; Conference Publishing Services.

Hirsch, B., Seubert, A., \& Sohn, M. (2015). Visualisation of data in management accounting reports. Journal of Applied Accounting Research, 16(2), 221-239. https://doi.org/10.1108/JAAR-08-2012-0059.

Hjortskov, N., Rissén, D., Blangsted, A. K., Fallentin, N., Lundberg, U., \& Søgaard, K. (2004). The effect of mental stress on heart rate variability and blood pressure during computer work. European Journal of Applied Physiology, 92(1-2), 84-89. https://doi.org/10.1007/s00421-004-1055-z.

Hofer, P., Walchshofer, C., Eisl, C., Mayr, A., \& Perkhofer, L. (2018). Sankey, Sunburst \& Co. Interactive big data visualizierungen im usability test. In L. Nadig, \& U. Egle (Eds.), Proceedings of CARF 2018. Controlling, accouting, risk, and finance. CARF Luzern 2018. Luzern, 06.-07.09.2018. (pp. 92-112). University of Applied Sciences Luzern: Verlag IFZ.

Inselberg, A., \& Dimsdale, B. (1990). Parallel coordinates. A tool for visualizing multi-dimensional geometry. In Proceedings of the First IEEE conference on visualization: visualization' 90. San Francisco, CA, USA, 23-26 Oct. 1990. (pp. 361-378). IEEE Comput. Soc. Press.

Isenberg, T., Isenberg, P., Chen, J., Sedlmair, M., \& Möller, T. (2013). A systematic review on the practice of evaluating visualization. IEEE Transactions on Visualization and Computer Graphics, 19(12), 2818-2827. 
Janvrin, D. J., Raschke, R. L., \& Dilla, W. N. (2014). Making sense of complex data using interactive data visualization. Journal of Accounting Education, 32(4), 31-48. https://doi.org/10.1016/j.jaccedu.2014. 09.003.

Johansson, J., \& Forsell, C. (2016). Evaluation of parallel coordinates. Overview, categorization and guidelines for future research. IEEE Transactions on Visualization and Computer Graphics, 22(1), 579-588. https://doi.org/10.1109/tvcg.2015.2466992.

Johnson, B., \& Shneiderman, B. (1991). Tree-maps: A space-filling approach to the visualization of hierarchical information structures. In Proceedings of the 2nd IEEE conference on visualization: visualization'91 (pp. 284-291). San Diego, CA, USA.

Kanjanabose, R., Abdul-Rahman, A., \& Chen, M. (2015). A multi-task comparative study on scatter plots and parallel coordinates plots. Computer Graphics Forum, 34(3), 261-270. https://doi.org/10.1111/ cgf. 12638 .

Kehrer, J., \& Hauser, H. (2013). Visualization and visual analysis of multifaceted scientific data. A survey. IEEE Transactions on Visualization and Computer Graphics, 19(3), 495-513. https://doi.org/10.1109/ tvcg.2012.110.

Keim, D. A. (2001). Visual exploration of large data sets. Communications of the ACM, 44(8), 38-44. https://doi.org/10.1145/381641.381656.

Keim, D. A. (2002). Information visualization and visual data mining. IEEE Transactions on Visualization and Computer Graphics, 8(1), 1-8. https://doi.org/10.1109/2945.981847.

Keim, D. A., Andrienko, G., Fekete, J.-D., Görg, C., Kohlhammer, J., \& Melancon, G. (2008). Visual analytics. Definition, process, and challenges. In A. Kerren, J. T. Stasko, J. D. Fekete, \& C. North (Eds.), Information visualization. Lecture notes in computer science (Vol. 4950, pp. 154-175). Berlin: Springer.

Keim, D. A., Mansmann, F., Schneidewind, J., \& Schreck, T. (Eds.) (2006). Monitoring network traffic with radial traffic analyzer. In 2006 IEEE symposium on visual analytics science and technology.

Kim, M., \& Draper, G. M. (2014). Radial vs. cartesian revisited. A comparison of space-filling visualizations. In Prodeedings of the VINCI'14. With assistance of ACM. 7th international symposium on visual information communication and interaction VINCI'14. Sydney, Australia, 05-08.08.2014 (pp. 196-199).

Lehmann, D. J., Albuquerque, G., Eisemann, M., Tatu, A., Keim, D., Schumann, H., et al. (2010). Visualisierung und Analyse multidimensionaler Datensätze. Informatik-Spektrum, 6(33), 589-600.

Liu, S., Maljovec, D., Wang, B., Bremer, P.-T., \& Pascucci, V. (2017). Visualizing high-dimensional data. Advances in the past decade. IEEE Transactions on Visualization and Computer Graphics, 23(3), 1249-1268. https://doi.org/10.1109/tvcg.2016.2640960.

Lurie, N. H., \& Mason, C. H. (2007). Visual representation: implications for decision making. Journal of Marketing, 71(1), 160-177.

Mansmann, F., Göbel, T., \& Cheswick, W. (2012). Visual analysis of complex firewall configurations. In D. Schweitzer \& D. Quist (Eds.), Proceedings of the ninth international symposium on visualization for cyber security (VisSec'12). Seattle, Washington, USA, 15.10.2012 (pp. 1-8). ACM.

Miller, G. A. (1956). The magical number seven, plus or minus two. Some limits on our capacity for processing information. Psychological Review, 101(2), 343-352.

Munzner, T. (2014). Visualization analysis and design. AK Peters visualization series (1st ed.). Boca Raton: CRC Press.

Netzel, R., Vuong, J., Engelke, U., O’Donoghue, S., Weiskopf, D., \& Heinrich, J. (2017). Comparative eye-tracking evaluation of scatterplots and parallel coordinates. Visual Informatics, 1(2), 118-131. https://doi.org/10.1016/j.visinf.2017.11.001.

Ohlert, C. R., \& Weißenberger, B. E. (2015). Beating the base-rate fallacy: An experimental approach on the effectiveness of different information presentation formats. Journal of Management Control, 26(1), 51-80. https://doi.org/10.1007/s00187-015-0205-2.

Pasch, T. (2019). Strategy and innovation: The mediating role of management accountants and management accounting systems' use. Journal of Management Control, 30(2), 213-246. https://doi.org/10.1007/ s00187-019-00283-y.

Perkhofer, L. M. (2019). A cognitive load-theoretic framework for information visualization. In O. Lehner (Ed.), Proceedings of the 17th conference on finance, risk and accounting perspectives, in Print (FRAP). Helsinki, 23.-25.09.2019 (pp. 9-25). ACRN Oxford.

Perkhofer, L., Hofer, P., \& Walchshofer, C. (2019a). BIG data visualisierungen 2.0. Optimale Gestaltung und Einsatz neuartiger Visualisierungsmöglichkeiten. In L. Nadig (Ed.), Proceedings of CARF 2019. 
Controlling, accounting, risk and finance. CARF Luzern 2019. Luzern, 5.-6.9.2019 (pp. 76-104). University of Applied Sciences Luzern: Verlag IFZ.

Perkhofer, L. M., Hofer, P., Walchshofer, C., Plank, T., \& Jetter, H.-C. (2019b). Interactive visualization of big data in the field of accounting. Journal of Applied Accounting Research, 5(1), 78. https://doi.org/ 10.1108/JAAR-10-2017-0114.

Perkhofer, L., \& Lehner, O. (2019). Using gaze behavior to measure cognitive load. In F. Davis, R. Riedl, J. Vom Brocke, P.-M. Léger, \& A. Randolph (Eds.), Information systems and neuroscience. NeuroIS Retreat 2018. Lecture notes in information systems and organisation, NeuroIS Retreat 2018 (1st ed., Vol. 29, pp. 73-83). Berlin: Springer.

Perkhofer, L., Walchshofer, C., \& Hofer, P. (2019c). Designing visualizations to identify and assess correlations and trends. An experimental study based on price developments. In O. Lehner (Ed.), Proceedings of the 17th conference on finance, risk and accounting perspectives (FRAP). Helsinki, 23.-25.09.2019 (pp. 294-340). ACRN Oxford.

Perrot, A., Bourqui, R., Hanusse, N., \& Auber, D. (2017). HeatPipe: High throughput, low latency big data heatmap with spark streaming. In 21st international conference on information visualization 2017. Information visualization 2017. London, UK, 11-14.07.2017. IVS (pp. 1-6). https://hal.archivesouvertes.fr/hal-01516888/document. Retrieved Dec 2018

Pike, W. A., Stasko, J., Chang, R., \& O'Connell, T. A. (2009). The science of interaction. Information Visualization, 8(4), 263-274. https://doi.org/10.1057/ivs.2009.22.

Plaisant, C., Fekete, J.-D., \& Grinstein, G. (2008). Promoting insight-based evaluation of visualizations. From contest to benchmark repository. IEEE Transactions on Visualization and Computer Graphics, 14(1), 120-134. https://doi.org/10.1109/tvcg.2007.70412.

Pretorius, J., \& van Wijk, J. (2005). Multidimensional visualization of transition systems. In E. Banissi, M. Sarfraz, J. C. Roberts, B. Loften, A. Ursyn, \& R. A. Burkhard et al. (Eds.), Proceedings of the ninth international conference on information visualization (IV'05). London, UK, 06.-08.07.2005 (pp. 1-6). IEEE Computer Society.

Riehmann, P., Hanfler, M., \& Froehlich, B. (2005). Interactive Sankey diagrams. In IEEE symposium on information visualization (InfoVis). Minneapolis, USA, 23.-25.10.2005 (pp. 233-240). IEEE Computer Society.

Rodden, K. (2014). Applying a sunburst visualization to summarize user navigation sequences. IEEE Computer Graphics and Applications, 34(5), 36-40. https://doi.org/10.1109/MCG.2014.63.

Satyanarayan, A., Moritz, D., Wongsuphasawat, K., \& Heer, J. (2017). Vega-Lite: A grammar of interactive graphics. IEEE Transactions on Visualization and Computer Graphics, 23(1), 341-350. https://doi. org/10.1109/TVCG.2016.2599030.

Severino, R. (2015). The data visualization catalogue-An online Blog. Heatmap. Tableau. Retrieved June 21, 2019 from https://datavizcatalogue.com/methods/heatmap.html.

Shaft, T. M., \& Vessey, I. (2006). The role of cognitive fit in the relationship between software comprehension and modification. MIS Quarterly, 30(1), 29-55.

Shneiderman, B. (1996). The eyes have it. A task by data type taxonomy for information visualization. In IEEE 1996. Proceedings, August 14-16, 1996, Blue Mountain Lake, New York. New York State Center for Advanced Technology in Computer Applications and Software Engineering (Syracuse University) (pp. 336-343). IEEE Computer Society. Los Alamitos Calif.: IEEE Computer Society Press.

Singh, K., \& Best, P. (2019). Anti-money laundering: Using data visualization to identify suspicious activity. International Journal of Accounting Information Systems, 34, 100418. https://doi.org/10.1016/j.accinf. 2019.06.001.

Songer, A. D., Hays, B., \& North, C. (2004). Multidimensional visualization of project control data. Construction Innovation, 4(3), 173-190. https://doi.org/10.1108/14714170410815088.

Speier, C. (2006). The influence of information presentation formats on complex task decision-making performance. International Journal of Human-Computer Studies, 64(11), 1115-1131.

Stab, C., Breyer, M., Nazemi, K., Burkhardt, D., Hofmann, C., \& Fellner, D. (2010). SemaSun: Visualization of semantic knowledge based on an improved sunburst visualizatioon metaphor. In J. Herrington \& C. Montgomerie (Eds.), Proceedings of ED-MEDIA 2010. World conference on educational multimedia, hypermedia \& telecommunications. Toronto, Canada, 29.06.2010. (pp. 911-919). Association for the Advancement of Computing in Education (AACE).

Stasko, J., \& Zhang, E. (2000). Focus + context display and navigation techniques for enhancing radial, space-filling hierarchy visualizations. In Proceedings of the INFOVIS 2000. IEEE symposium on information visualization 2000. Salt Lake City, Utah, 09-10.10.2000 (pp. 57-65). ACM SIGGRAPH. 
Sweller, J. (2010). Element interactivity and intrinsic, extraneous, and germane gognitive load. Educational Psychology Review, 22(2), 123-138.

Tufte, E. R. (1983). The visual display of quantitative information (1st ed.). Connecticut: Graphics Press. van Wijk, J. J. (2005): The value of visualization. In Proceedings of the 2005 IEEE VIS. IEEE visualization. Minneapolis, MN, USA, 23-28. Oct. 2005 (pp. 79-86).

van Wijk, J. J. (2013). Evaluation. A challenge for visual analytics. Computer, 46(7), 56-60. https://doi. org/10.1109/mc.2013.151.

Vessey, I., \& Galletta, D. (1991). Cognitive fit: An empirical study of information acquisition. Information Systems Research, 2(1), 63-84.

Wang, L., Wang, G., \& Alexander, C. (2015). Big data and visualization. Methods, challenges, and technology progress. Digital Technologies, 1(1), 33-38. https://doi.org/10.1002/9781119197249.ch1.

Ware, C. (2012). Information visualization. Perception for design (3rd ed.). Oxford: Elsevier Ltd.

Wilkinson, L. (2005). The grammar of graphics (Vol. 2). New York: Springer.

Yi, J. S., Kang, Y. A., Stasko, J., \& Jacko, J. (2007). Toward a deeper understanding of the role of interaction in information visualization. IEEE Transactions on Visualization and Computer Graphics, 13(6), 1224-1231. https://doi.org/10.1109/TVCG.2007.70515.

Yigitbasioglu, O. M., \& Velcu, O. (2012). A review of dashboards in performance management: Implications for design and research. International Journal of Accounting Information Systems, 13(1), 41-59.

Zhou, M. X., \& Feiner, S. K. (1998). Visual task characterization for automated visual discourse synthesis. In Proceedings of the SIGCHI conference on human factors in computing systems. CHI 98. Los Angeles, C.A., USA, 18.-23.04.1998 (pp. 392-399). ACM.

Publisher's Note Springer Nature remains neutral with regard to jurisdictional claims in published maps and institutional affiliations. 